\title{
Anxiety, Advice, and the Ability to Discern: Feeling Anxious Motivates Individuals to Seek and Use Advice
}

\section{Citation}

Gino, F., A. Brooks, and M. Schweitzer. "Anxiety, Advice, and the Ability to Discern: Feeling Anxious Motivates Individuals to Seek and Use Advice." Journal of Personality and Social Psychology 102, no. 3 (March 2012): 497-512.

\section{Permanent link}

http://nrs.harvard.edu/urn-3:HUL.InstRepos:10996805

\section{Terms of Use}

This article was downloaded from Harvard University's DASH repository, and is made available under the terms and conditions applicable to Open Access Policy Articles, as set forth at http:// nrs.harvard.edu/urn-3:HUL.InstRepos:dash.current.terms-of-use\#OAP

\section{Share Your Story}

The Harvard community has made this article openly available. Please share how this access benefits you. Submit a story.

Accessibility 
RUNNING HEAD: Anxiety and Advice taking

Anxiety, Advice, and the Ability to Discern:

Feeling Anxious Motivates Individuals to Seek and Use Advice

\author{
Francesca Gino ${ }^{1}$ \\ Alison W. Brooks ${ }^{2}$ \\ Maurice E. Schweitzer ${ }^{2}$ \\ ${ }^{1}$ Harvard University, ${ }^{2}$ University of Pennsylvania
}

Forthcoming, Journal of Personality and Social Psychology

The authors thank the Computer Lab for Experimental Research (CLER) at Harvard Business School and the Center for Decision Research (CDR) at the University of North Carolina at Chapel Hill for facilities. The authors also thank Harvard Business School and the Wharton School for financial support. The authors are grateful to Jennifer Fink and Leslie Talbott for their help with data collection. Please address correspondence to fgino@hbs.edu. 


\begin{abstract}
Across eight experiments, we describe the influence of anxiety on advice seeking and advice taking. We find that anxious individuals are more likely to seek and rely on advice than are those in a neutral emotional state (Experiment 1), but this pattern of results does not generalize to other negatively-valenced emotions (Experiment 2). The relationships between anxiety and advice seeking and anxiety and advice taking are mediated by self-confidence; anxiety lowers selfconfidence, which increases advice seeking and reliance upon advice (Experiment 3). Though anxiety also impairs information processing, impaired information processing does not mediate the relationship between anxiety and advice taking (Experiment 4). Finally, we find that anxious individuals fail to discriminate between good and bad advice (Experiment 5a-c), and between advice from advisors with and without a conflict of interest (Experiment 6).
\end{abstract}

Keywords: Anxiety; Advice taking; Emotions; Self-confidence; Conflict of Interest 
When individuals face important decisions, such as how to invest savings or how to choose a course of medical treatment, they often feel anxious and seek advice from colleagues, friends, and experts. Anxiety is "a state of distress and/or physiological arousal in reaction to stimuli including novel situations and the potential for undesirable outcomes" (Brooks \& Schweitzer, 2011, p. 44). Prior research has documented harmful effects of anxiety on decision making. For example, anxiety impairs the ability to process information (e.g., Eysenck, 1992; Ganzer, 1968; Sengupta \& Johar, 2001; Zatz \& Chassin, 1985).

In addition to experiencing anxiety, when making important decisions, people frequently seek advice from colleagues, friends, and experts. Drawing on previous research on the role of anxiety in decision making, we investigate how anxiety influences advice seeking and advice taking. Departing from previous work, we propose that anxiety harms individuals' confidence in their ability to make good decisions. As a result, individuals with impaired self-confidence are motivated to seek advice from others and rely on it, even when the advice they receive is bad. This line of research advances our understanding of how anxiety influences decision making by considering the motivational, in addition to the cognitive, consequences of experiencing anxiety. $\underline{\text { Advice }}$

We define advice as any relevant ideas and judgments that are offered to a decision maker. Our definition of advice includes contexts in which advisors are disinterested in the advisee's decision and outcome as well as contexts in which advisors are invested in the advisee's decision and outcome, as in the case of helping behavior and persuasion.

In general, the process of seeking and receiving advice from others can expose an advisee to a conflict between their initial judgment and the advice they receive (Yaniv \& Kleinberger, 2000). For example, a homebuyer may plan to make an offer of $\$ 400,000$ to a seller. Before the 
buyer makes an offer, however, she may consult her realtor, who may advise her to offer $\$ 440,000$ to avoid insulting the seller. Although little prior research has explored the adviceseeking process, a growing literature has investigated advice taking. This work identifies three factors that influence how receptive individuals are to advice.

First, characteristics of the advisor matter. Individuals weight advice more heavily when advisors are more experienced or more knowledgeable than the decision makers themselves (Goldsmith \& Fitch, 1997; Feng \& MacGeorge, 2006; Harvey \& Fischer, 1997; Sniezek, Schrah, \& Dalal, 2004; Yaniv, 2004; Yaniv \& Kleinberger, 2000; Yaniv \& Milyavsky, 2007). People are similarly more likely to weight advice when advisors express confidence in the quality of their advice (Sniezek \& Buckley, 1995; Sniezek \& Van Swol, 2001; Tost, Gino, \& Larrick, in press; Van Swol \& Sniezek, 2005; Yaniv, 1997).

Second, characteristics of the decision task moderate how receptive individuals are to advice. For example, individuals weigh advice more heavily when the task is difficult than when it is easy (Gino \& Moore, 2007) and when advice is costly to obtain than when it is free (Gino, 2008; Patt, Bowles, \& Cash, 2006).

Third, aspects of the decision maker's internal state impact how receptive individuals are to advice, such as the decision maker's confidence (Cooper, 1991) and emotional state (e.g., Gino \& Schweitzer, 2008).

The extant advice-taking literature has also identified a surprising regularity: in almost every domain, individuals discount the advice they receive (see Bonaccio \& Dalal, 2006 for a review). In contrast to this finding, we identify an important aspect of a decision maker's internal state that causes individuals to be very receptive to advice: anxiety. We postulate that anxiety promotes feelings of low self-confidence. Compared to individuals in a neutral emotional state, 
we expect anxious individuals to lack confidence in their ability to make good judgments. As a result, we predict that anxious individuals will become more likely to seek advice and to rely on the advice they receive, even when the advice is bad.

$\underline{\text { Anxiety }}$

Anxiety is triggered by uncertain and novel situations that have the potential for adverse consequences (Brooks \& Schweitzer, 2011). For example, an inexperienced homebuyer who is concerned about losing the opportunity to buy a desirable home may feel anxious when making an offer. Anxiety is a common emotion that signals the presence of a potential threat, promotes pessimistic appraisals of future events, and triggers psychological responses that help individuals reduce their vulnerability (Barlow, 1988; Butler \& Mathews, 1983, 1987; Raghunathan \& Pham, 1999; Savitsky, Medvec, Charlton, \& Gilovich, 1998; Shepperd, Grace, Cole, \& Klein, 2005; Young, Klap, Shoai, \& Wells, 2008). Extant anxiety research has largely focused on trait anxiety (e.g., Endler, 1980; Eysenck, 1982, 1992, 1997; Kantor, Endler, Heslegrave, \& Kocovski, 2001; Stober, 1997), a personality characteristic similar to neuroticism that reflects an individual's susceptibility to anxious feelings (Spielberger, 1985). Individuals with high trait anxiety and those with anxiety disorders experience anxious feelings frequently.

In this paper we focus on state anxiety, a transient emotion that anyone can experience. Unlike trait anxiety, state anxiety is relatively short-lived, often occurring for mere seconds or minutes. Consistent with prior research (see Brooks \& Schweitzer, 2011; Gray, 1991), we conceptualize anxiety to subsume fear, tension, worry, nervousness, stress, and apprehension. Anxiety is an unpleasant and aversive emotion (Marks \& Nesse, 1994) that is characterized by high activation (within Russell's [1980] affective circumplex model), high uncertainty, and low control (within Smith and Ellsworth's [1985] appraisal framework). 
State anxiety can be directed or incidental. In contrast to directed emotions that are triggered by an aspect of the decision context itself (e.g., by the nature of the decision or the people involved), incidental emotions are triggered by a prior stimulus that is unrelated to the current decision (e.g., Lerner \& Keltner, 2001). For example, an individual who plans to invest in the stock market might experience directed anxiety because he is worried about losing money in the market, incidental anxiety because he watched an anxiety-inducing movie before making an investment decision, or both. In this paper, we study incidental anxiety because it offers a conservative test of the influence of anxiety on advice taking. There are no normative reasons for why incidental anxiety should influence behavior.

\section{Anxiety, Advice Seeking, and Advice Taking}

Schwartz and Clore's (1983) affect-as-information model suggests that individuals rely on the characteristics of their feelings to inform their judgments and decisions (Pham, 1998; Clore, Gasper, \& Garvin, 1998; Frijda, 1986; Raghunathan \& Pham, 1999; Schwartz, 1990; Schwartz \& Clore, 1988). Anxiety is characterized by high uncertainty and low control about an outcome. Both low certainty and low control cue implicit goals of reducing uncertainty and increasing control (Fridja, Kuipers, \& ter Schure, 1989; Izard, 1977; Raghunathan \& Pham, 1999). As a result, anxiety may cause individuals to prefer options that reduce risk and uncertainty even when the decision task is unrelated to the anxiety-inducing stimulus (Brooks \& Schweitzer, 2011; Raghunathan, Pham, \& Corfman, 2006).

One approach to reducing uncertainty is to strengthen social relationships. In fact, anxiety increases the need for social affiliation (e.g., Schachter, 1959; Taylor, 2006). A healthy social network can improve an individual's physical and mental ability to cope with anxiety, whereas 
social exclusion decrease levels of belongingness, control, self-esteem, and meaning (Taylor, 2000; Zadro, Williams, \& Richardson, 2004).

We suggest that in the case of decision making, individuals use a similar approach to reducing uncertainty generated by anxiety: they gather information from others and use it to make decisions. Uncertainty harms general self-efficacy, or the belief that one is capable of attaining a specific, desirable goal (Bandura, 1977, 1997; Gould, Petlichkoff, \& Weinberg, 1984; Martens, Burton, Vealey, Bump, \& Smith, 1990; Martin \& Gil, 1991), and erodes selfconfidence (Maddux, 1995; Schunk, 1995). Building on this work, we predict that, compared to individuals in a neutral emotional state, anxious individuals will feel uncertain of their ability to make good decisions and will have low confidence in their own judgments. As a result, they will be more likely to seek advice from others and to rely more heavily on the advice they receive.

Confident individuals are less receptive to advice than unconfident individuals are (e.g., Gino \& Moore, 2007; Harvey \& Fischer, 1997; Yaniv \& Kleinberger, 2000; Yaniv, 2004). As a result, we expect individuals with low confidence in their judgments due to anxiety to weight others' advice more heavily than people with high confidence. Taken together, we expect selfconfidence to mediate the relationships between anxiety and advice seeking and between anxiety and advice taking.

Anxiety and the Ability to Discriminate Between Good and Bad Advice

Individuals are generally sensitive to the quality of the advice they receive. Yaniv and Kleinberger (2000) found that individuals are more receptive to good advice than they are to bad advice. We expect anxious individuals, however, to be less discerning than neutral individuals. Anxiety harms self-confidence. Low confidence causes individuals to place low weight on their own estimates and to create a wide confidence interval around their own judgments. With a wide 
confidence interval, individuals will consider a large set of values or ideas to be reasonable. As a result, anxious individuals are more likely than neutral individuals to consider bad advice to be reasonable or acceptable.

For similar reasons, we expect anxious individuals, compared to non-anxious individuals, to rely more heavily on advice from advisors with a conflict of interest. Conflicted advisors often allow their personal preferences to influence the advice they offer others (Cain, Loewenstein, \& Moore, 2005, 2011). In general, advisees, even when they are aware of the conflict of interest, rely heavily on the advice they receive (Cain et al., 2005, 2011). By eroding confidence, we expect anxiety to exacerbate this problem. Specifically, by eroding self-confidence, we expect anxiety to cause individuals to consider a wide range of advice values as reasonable. As a result, anxious individuals are likely to consider even biased advice from a conflicted advisor as reasonable. Low confidence also causes anxious advisees to place low weight on their own estimates relative to the weight they place on the advice of others. Taken together, we predict that anxious individuals will rely more heavily on advice from an advisor with a conflict of interest than non-anxious individuals.

Importantly, we do not develop specific hypotheses with respect to anxiety and accuracy. The influence of anxiety on accuracy is likely to be moderated by a number of factors, such as the accuracy of an individual's initial judgments, the accuracy of advice, and an individual's initial receptivity to advice. For example, if an anxious individual makes an accurate initial judgment and receives bad advice, his final judgment may be less accurate than his initial judgment. On the other hand, if his initial judgment was inaccurate and he receives very good advice, his final judgment is likely to become more accurate. 


\section{Overview of the Present Research}

Compared to individuals in a neutral state, we expect anxious individuals to be more likely to seek advice and to use advice, even if the advice is of low quality. We expect the relationship between anxiety and receptivity to advice to be mediated by low self-confidence. We depict our theoretical model in Figure 1.

We test our hypotheses in eight experiments. In Experiment 1, we induce incidental anxiety and measure how likely participants are to seek and take advice from others. In Experiment 2, we compare the effects of incidental anger to those of incidental anxiety and demonstrate that these two emotions, though both negatively valenced, affect advice taking differently. Compared to a control condition, anger decreases advice taking and anxiety increases it. In Experiment 3, we show that anxiety lowers self-confidence, which, in turn, promotes advice taking. In Experiment 4, we disentangle cognitive from motivational mechanisms to explain the link between anxiety and advice taking. We show that low self-confidence mediates the relationship between anxiety and advice taking but that impaired information processing does not. In Experiments 5a-c, we examine whether anxiety harms the ability to discriminate between good and bad advice. In Experiment 6, we examine whether anxiety harms the ability to discriminate between advice from advisors with or without a conflict of interest. Across our studies, we use different emotion inductions to trigger anxiety (e.g., movie clips, audio clips, and writing tasks) and different decision tasks.

Our work makes several theoretical contributions. First, we extend our understanding of the influence of state anxiety on self-confidence and subsequent decision making. Previous research has examined the cognitive consequences of experiencing anxiety; here, we investigate its motivational consequences. Second, we expand our understanding of the advice-taking 
process (e.g., Bonaccio \& Dalal 2006; Larrick \& Soll, 2006). In particular, we identify the importance of self-confidence and the ability to discern between good and bad advice. Third, though a growing literature has examined advice taking, our work examines the relatively understudied process of advice seeking. Fourth, our work extends understanding of how specific emotions influence decision making in interpersonal settings (e.g., Ashfort \& Humphrey, 1995; Brief \& Weiss, 2002).

\section{Experiment 1: The Effect of Anxiety on Advice Seeking and Advice Taking}

In Experiment 1, we examine how anxiety influences advice seeking and advice taking. We also explore the role of self-confidence as a mediator.

\section{$\underline{\text { Method }}$}

\section{$\underline{\text { Participants }}$}

One hundred and two college students (56 female, $\left.M_{a g e}=21, S D=1.34\right)$ at a university in the Southern United States participated in the study for pay. Participants received a \$2 show-up fee and had the opportunity to earn an additional \$6 during the study.

\section{$\underline{\text { Design and Procedure }}$}

Participants sat in private computer cubicles and were randomly assigned to one of two emotion conditions (anxiety vs. neutral). To mitigate potential demand effects, we informed participants that the experiment included two unrelated studies, a "Weight Estimation Study" (two parts) and a "Vivid Recall Study." All of the study materials were presented on the computer screen.

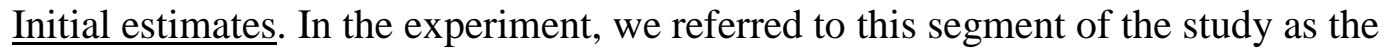
“Weight Estimation Study (Part 1)." Participants completed a repeated judgment task. In each of three rounds, we showed participants a photo of a stranger and asked them to estimate the 
person's weight. As an incentive to be accurate, we gave participants a $\$ 1$ bonus if their estimate fell within ten pounds of the actual weight of the person in the photo.

Emotion induction. We referred to this segment of the experiment as the "Vivid Recall Study." Participants were told that they would be watching a video clip and that they would be asked to recall details from the video clip later in the study. In this segment of the experiment, we randomly assigned participants to watch either an anxiety-inducing clip from the movie Vertical Limit about a mountain-climbing accident or a neutral clip from a National Geographic documentary about fish in the Great Barrier Reef. Both video clips have been used in prior emotion research to induce anxiety and neutral feelings (e.g., Brooks \& Schweitzer, 2011; Frederickson \& Branigan, 2005; Gino \& Schweitzer, 2008; Gross \& Levenson, 1995).

Measure of self-confidence. In the segment of the experiment after the emotion induction, participants completed a four-item self-confidence measure (adapted from Schwarzer \& Jerusalem, 1995). This measure included items such as "I feel capable" and "I usually make good judgments" $(\alpha=.96)$.

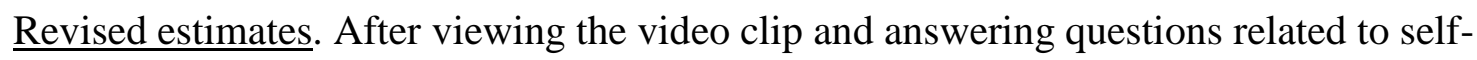
confidence, participants made a second round of estimates. We referred to this part of the experiment as the "Weight Estimation Study, Part 2." We asked participants to re-estimate the weight of the same three people they saw in Part 1 , and told them they would receive a $\$ 1$ bonus every time their estimate fell within ten pounds of the actual weight of the person in the photograph. Before showing participants the three photographs, we asked them to indicate whether they wanted to receive advice from another participant. Participants answered this question only once before making their estimates. If they chose to receive advice, we showed them the estimates that another participant had purportedly made for the same set of photos in 
addition to their own initial estimates. If they did not choose to receive advice, participants only saw their own initial estimates. For experimental control, we kept the three advice values constant across conditions. We explained that these values had been randomly chosen from estimates participants in a previous study had made when they were assigned to the role of advisor and were paid based upon the accuracy of their estimates. In each round, the advice was of good quality, falling within $5 \%$ of the true weight of the person in each photo.

Emotion measures. Next, we asked participants to think back to the video clip and to indicate the extent to which they felt various emotions (Lerner \& Keltner, 2001; Lerner et al., 2004).

\section{$\underline{\text { Dependent Measures }}$}

Advice seeking. To assess advice seeking, we examined whether or not participants chose to receive advice before making their second set of estimates $(1=y e s, 0=$ no).

Advice taking. Consistent with prior advice-taking research, we used the "weight of advice" (WOA) measure to assess participants' receptivity to advice. This measure gauges the extent to which participants revise their estimates in the direction of the advisor's estimate (Harvey \& Fischer, 1997; Yaniv \& Foster, 1997). The WOA measure ranges from zero, which indicates that the advice has no impact on an individual's final estimate, to one, which indicates that the final estimate is equal to the advice. The WOA measure is computed as follows:

$$
W O A=\frac{\mid \text { final estimate }- \text { initial estimate } \mid}{\mid \text { advice }- \text { initial estimate } \mid} .
$$

If participants believe that they and their advisors are equally well informed, they should weight their own and another person's estimate equally, and the WOA score would equal 0.5 (Larrick \& Soll, 2006). 
Pilot study. We pilot-tested the emotion induction clips with a non-overlapping sample of participants $(N=42)$. In the pilot study, we asked participants to watch one of the two video clips and rate the emotions they experienced immediately after watching the clip. To measure anxiety, we averaged responses for anxious, tense, and distressed $(\alpha=.92)$. To measure neutral feelings, we averaged responses for neutral, indifferent, and unemotional $(\alpha=.84)$. The results of the pilot study confirmed that these video clips effectively induce anxiety and neutral feelings.

Participants reported higher feelings of anxiety when they watched the anxiety-inducing video $\operatorname{clip}(M=4.27, S D=2.37)$ than when they watched the neutral clip $(M=1.79, S D=1.41), t(40)=4.12$, $p<.001$. In addition, participants reported higher neutral feelings when they watched the neutral clip $(M=5.44, S D=2.05)$ than when they watched the anxiety-inducing one $(M=2.54, S D=1.91)$, $t(40)=4.76, p<.001$.

\section{$\underline{\text { Results }}$}

Across all of our studies, we first conducted analyses that included gender and age as independent variables. We found no main effects or interaction effects for these demographic variables, and we report all of our findings collapsed across demographic groups.

Emotion Manipulation Check. Feelings of anxiety were higher in the anxiety condition $(M=6.83, S D=1.45)$ than in the neutral condition $(M=1.75, S D=1.06), t(100)=20.04, p<.001$, and neutral feelings were higher in the neutral condition $(M=4.37, S D=1.70)$ than in the anxiety condition $(M=2.44, S D=1.67), t(100)=5.80, p<.001$. These results suggest that our emotion induction was effective.

Advice Seeking. Consistent with our prediction that anxious individuals would be more likely to seek advice than would individuals in a neutral state, $90 \%(47 / 52)$ of participants in the 
anxiety condition sought advice, compared to $72 \%(36 / 50)$ in the neutral condition, $\chi^{2}(1, N=102)=5.68, p<.02$.

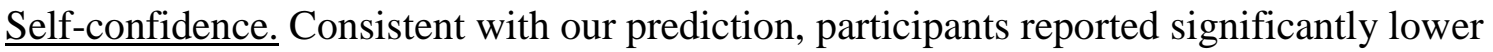
self-confidence in the anxiety condition $(M=4.87, S D=1.84)$ than in the neutral condition $(M=6.21, S D=0.63), t(100)=-4.86, p<.001$.

We then examined whether self-confidence mediated the relationship between incidental anxiety and advice seeking (Baron \& Kenny, 1986). As summarized in Table 1, by including self-confidence in our model, the influence of anxiety on advice seeking was reduced to nonsignificance (from $\beta=.24, p<.02$ to $\beta=.13, p=.24$; $95 \%$ bias-corrected CI, $[.04, .15]$ ), and selfconfidence predicted advice seeking $(\beta=-.26, p<.02) .{ }^{1}$ These findings demonstrate that selfconfidence mediates the relationship between anxiety and advice seeking.

Advice Taking. We next examined whether incidental anxiety influenced advice taking by using data only from participants who chose to seek advice before making their revised estimates. As predicted, results from a repeated-measures ANOVA demonstrate that advice taking was higher in the anxiety condition $(M=0.55, S D=0.26)$ than in the neutral condition $(M=0.39, S D=0.11), F(1,81)=11.55, p=.001, \eta_{p}{ }^{2}=.13$.

\section{$\underline{\text { Discussion }}$}

Results from Experiment 1 demonstrate that incidental anxiety increases both advice seeking and advice taking. Furthermore, our results indicate that incidental anxiety harms selfconfidence, and that self-confidence mediates the relationship between incidental anxiety and advice seeking.

\footnotetext{
${ }^{1}$ In this study, because our dependent variable was binary, we reran the mediation analyses using MacKinnon and Dwyer's (1993) logistic regression method and found the same pattern of results. We report the more traditional approach in the interest of parsimony.
} 


\section{Experiment 2: The Influence of Anxiety and Anger on Advice Taking}

In Experiment 2, we extend our investigation of the relationship between anxiety and advice taking by contrasting the influence of two negatively valenced emotions: anxiety and anger. Although a substantial literature documents the misattribution of the valence of emotions (e.g., Dunn \& Schweitzer, 2005), we postulate that it is the certainty dimension of anxiety, not valence, that causes individuals to be more receptive to advice. Smith and Ellsworth's (1985) appraisal theory of emotions characterizes emotions across several dimensions. Anxiety and anger, though both negatively valenced, differ along the dimension of certainty. Anxiety is characterized by a sense of uncertainty, whereas anger is characterized by a sense of certainty.

Consistent with our theoretical framework, we expect anxious feelings to increase feelings of uncertainty, lower self-confidence, and increase advice taking. Conversely, we expect anger to increase feelings of certainty, increase confidence, and decrease advice taking. Compared to individuals in a neutral state, we expect anxious individuals to be more receptive to advice, and we expect angry individuals to be less receptive to advice. We expect self-confidence to mediate these relationships.

\section{Method}

\section{$\underline{\text { Participants }}$}

One hundred twenty-seven students ( 74 female, $M_{a g e}=21.10, S D=2.56$ ) at a university in the Southern United States participated in the study for pay. Participants received a $\$ 2$ show-up fee and had the opportunity to earn an additional $\$ 6$ during the study.

\section{$\underline{\text { Design and Procedure }}$}

Participants were randomly assigned to one of three emotion-induction conditions: anxiety, anger, or neutral. We used the same procedure as in Experiment 1, with three important 
differences. First, in Experiment 2, in addition to an anxiety and a neutral condition, we included an anger condition. In the anger condition, participants watched a video clip from the movie $M y$ Bodyguard that portrays a man being treated unfairly. This video clip has been effectively used in prior research to induce incidental anger (Gino \& Schweitzer, 2008). Consistent with this design change, we added three additional emotions to assess anger (i.e., angry, mad, and furious, $\alpha=.84$ ) in the measure of subjective feelings participants completed at the end of the study.

Second, we developed a different measure to assess participants' self-confidence. We developed this measure to capture certainty and perceived accuracy of one's own estimates. This measure of self-confidence included five items $(\alpha=.76)$ : "I think my initial estimates are accurate," "I think my initial estimates are close to the true value," "I am very certain about the accuracy of my judgments," "I am sure I am performing well on this task," and "I have no doubt my estimates are close to the true values." Participants indicated their agreement with each item and other filler items using a seven-point scale ( $1=$ strongly disagree, $7=$ strongly agree). Half the participants answered these questions after the emotion induction, and half answered these questions after they made revised estimates.

Third, we did not ask participants whether or not they wanted to receive advice. Instead, across all three conditions, every participant received advice prior to making their revised estimates.

\section{$\underline{\text { Results }}$}

We found no order effects for whether participants answered the self-confidence questions after the emotion induction or after providing their revised estimates. Thus, we report our findings collapsed across order conditions. In Table 2, we report descriptive statistics for all of the variables we measured in this study. 
Emotion Manipulation Check. Consistent with our emotion induction, feelings of anxiety varied across conditions, $F(2,124)=36.88, p<.001, \eta_{p}{ }^{2}=.37$. Participants reported greater anxiety in the anxiety condition than they did in both the neutral condition and the anger condition (both $p s<.001)$; anxiety ratings did not differ in the latter two conditions $(p=.41)$. Neutral feelings also varied across conditions, $F(2,124)=4.92, p<.01, \eta_{p}{ }^{2}=.07$ : they were higher in the neutral condition than they were in both the anxiety condition and the anger condition (both $p s<.05$ ), and these ratings did not differ in the latter two conditions $(p=.30)$. Finally, anger ratings differed by condition, $F(2,124)=22.96, p<.001, \eta_{p}{ }^{2}=.27$ : they were higher in the anger condition than in both the anxiety condition and the neutral condition (both $p s<.001$ ), and anger ratings did not differ in the latter two conditions $(p=.44)$.

Advice Taking. A repeated-measures ANOVA revealed that advice use varied across conditions, $F(2,124)=20.06, p<.001, \eta_{p}{ }^{2}=.24$. Participants were more receptive to advice when they experienced incidental anxiety than when they experienced incidental anger or neutral feelings (both $p s<.01$ ). Furthermore, participants were less receptive to advice when they experienced incidental anger than when they experienced neutral feelings $(p<.01)$.

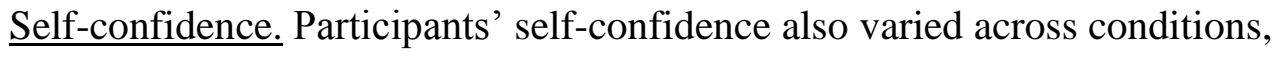
$F(2,124)=35.17, p<.001, \eta_{p}{ }^{2}=.36$; self-confidence was lower in the anxiety condition than in either the anger or the neutral condition (both $p$ 's<.001), and self-confidence was higher in the anger than in the neutral condition $(p<.001)$.

We next examined whether self-confidence mediated the effect of incidental anxiety on advice taking (see Table 1$).^{2}$ When we included self-confidence in the regression, the effect of

\footnotetext{
${ }^{2}$ In our regressions, we used the average WOA across the three rounds as the dependent variable and included a dummy variable for the anger condition.
} 
anxiety was reduced to non-significance ( $\operatorname{from} \beta=.29, p=.001$, to $\beta=.10, p=.27 ; 95 \%$ biascorrected CI, $[0.05,0.18])$, and self-confidence predicted advice use $(\beta=-.53, p<.001)$.

\section{$\underline{\text { Discussion }}$}

In Experiment 2, we extended our investigation of the link between anxiety and receptivity to advice by contrasting two negatively-valenced emotions, anger and anxiety. We find that negative valence cannot account for our findings in Experiment 1. Angry participants were less receptive to advice than were those in both the neutral and the anxiety conditions. We find that incidental anxiety reduces self-confidence and that this lowered self-confidence mediates the relationship between anxiety and advice taking.

\section{Experiment 3: Anxiety and Perceptions of Advice Quality}

In Experiment 3, we further test our theoretical model by using a different method of inducing anxiety and a different measure of advice taking. We also include a measure of advice quality to assess how anxiety influences perceptions of advice quality.

\section{$\underline{\text { Method }}$}

\section{$\underline{\text { Participants }}$}

Seventy-nine students ( 44 female, $M_{a g e}=23, S D=2.77$ ) at a university in the Southern United States participated in the study in exchange for a \$2 show-up fee and the opportunity to earn an additional $\$ 5$.

\section{Design and Procedure}

We randomly assigned participants to one of two experimental conditions: neutral vs. anxiety. In each condition, participants listened to a music clip designed to induce either anxiety or neutral feelings (see Brooks \& Schweitzer, 2011). As a cover story, we informed participants that they would participate in several unrelated studies. We informed participants that in one 
study we would ask them to evaluate music. We then asked participants to wear headphones and listen to an audio clip while performing other tasks. In the anxiety condition, participants listened to the theme music from the movie Psycho. In the neutral condition, participants listened to Handel's Water Music: Air. Neither audio clip included vocal parts, and each clip was played on a continuous loop.

After reading general instructions about the audio clips, we informed participants about another, ostensibly unrelated study titled "Individual Performance Under Time Pressure.” We told participants they had three minutes to work on a math problem and that they would receive a $\$ 5$ bonus for identifying the correct solution out of the five solutions provided. Furthermore, we told participants that they would receive information from another participant who previously completed the same task but had the opportunity to work on the problem for five minutes. Before working on the problem, participants received an envelope with a handwritten note, supposedly from this person, which read, "Choose Solution A [B, C, D, or E]." In this way, participants received advice from this person before they had the chance to work on the problem on their own. After reading the note, participants answered a series of questionnaires that included our measure of self-confidence (the same measure employed in Experiment 2, $\alpha=.79$ ). Next, they spent three minutes working on the problem.

Once the three minutes were over, participants indicated which solution they thought was correct among the five possible solutions. Thus, participants provided their answers after having the opportunity to work on the problem and after reporting their level of self-confidence. After choosing a solution, participants answered a series of questions that included target questions interspersed with distracter questions. Our target questions asked participants to assess the quality of the advice. Specifically, we asked participants to indicate on seven-point scales 
(1=very unlikely, $7=$ very likely) the extent to which the advice was likely to be accurate, was

likely to be of good quality, probably represented the right answer, and was likely to indicate the correct answer $(\alpha=.90)$. We also asked participants to indicate the extent to which the music made them feel various emotions.

\section{Pilot Study}

We conducted a pilot study with a non-overlapping sample of participants. Thirty-five students from local universities in the Southern United States (52\% male; $M_{\text {age }}=21, S D=2.69$ ) participated in the pilot study in exchange for $\$ 3$. In this pilot study, we gave participants five minutes to solve a math problem. After three minutes, we checked to see whether any of the participants had solved the problem. The problem (previously used by Dunn, Ruedy \& Schweitzer, 2011) read:

Two people are running around a square track. Each side of the track has a length of 11 meters. Person A and person B begin at opposite corners of the track, facing the same corner. If person A runs 3 meters per second and person B runs 5 meters per second, how many meters will person $B$ have run when they pass each other for the fourth time?

The correct solution is 96.25 meters. No participant solved the math problem correctly in three minutes, and only two participants out of 35 were able to solve the problem in the allotted five minutes. Consistent with Dunn et al. (2011), we found that this math problem appears tractable to participants, but is in fact quite difficult to solve.

\section{$\underline{\text { Results }}$}

Emotion Manipulation Check. Consistent with our induction, feelings of anxiety were higher in the anxiety condition $(M=5.73, S D=1.44)$ than in the neutral condition $(M=2.00$, $S D=1.36), t(77)=11.84, p<.001$. In addition, neutral feelings were higher in the neutral condition $(M=4.62, S D=1.78)$ than in the anxiety condition $(M=2.79, S D=1.77), t(77)=4.59, p<.001$. 
Advice Taking. To measure advice taking, we coded the correspondence between advisors' recommendations and participants' choices. If a participant's choice matched the advice, we coded the response as 1 , and 0 otherwise. Sixty-eight percent of the participants (27/40) took the advice in the anxiety condition, while only $41 \%$ of participants $(16 / 39)$ took the advice in the neutral condition, $\chi^{2}(1, N=79)=5.58, p<.05$.

Advice Quality. Similarly, perceived advice quality was higher in the anxiety condition $(M=5.07, S D=1.43)$ than in the neutral condition $(M=4.27, S D=1.38), t(77)=2.53, p<.05$.

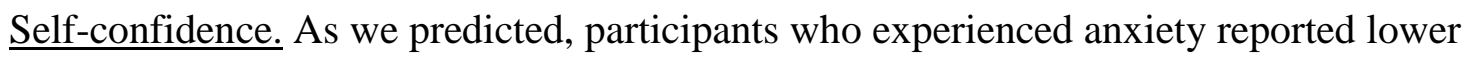
self-confidence $(M=3.62, S D=1.06)$ than did participants in the neutral condition $(M=3.00$, $S D=0.79, t(77)=2.92, p=.005$.

We also conducted mediation analyses (see Table 1) and found that self-confidence mediated the relationship between our emotion manipulation and participants' perceptions of advice quality $(95 \%$ bias-corrected CI, $[0.19,1.11])$ as well as the relationship between anxiety and advice taking (95\% bias-corrected CI, [0.24, 2.04]).

\section{$\underline{\text { Discussion }}$}

In Experiment 3, we again demonstrate that anxiety decreases confidence in one's own estimates, increases perceptions of advice quality, and increases receptivity to advice. This experiment extends our investigation by replicating these relationships with a different emotion induction and a different advice-taking task.

\section{Experiment 4: Self-Confidence and Information Processing as Potential Mediators}

In Experiments 1-3, we identify lower self-confidence as the mechanism that mediates the relationships between anxiety and advice seeking and between anxiety and advice taking. In 
Experiment 4, we consider an alternative mediator for the relationship between anxiety and advice taking: impaired information processing.

In addition to lowering self-confidence, anxiety impairs the ability to process information (Eysenck, 1982; Sengutpa \& Johar, 2001). As a result, anxious individuals perform poorly on tasks that demand cognitive resources (Chen, 1996; Deffenbacher, 1977; Hamilton, 1975; Ganzer, 1968; Mueller, 1976). When individuals feel anxious, they divert cognitive resources to activities such as worrying, retain fewer cognitive resources for the task at hand (Eysenck, 1979, 1982), and take longer to draw inferences (e.g., Darke, 1988).

In Experiment 4, we use the Stroop task (Stroop, 1935) to assess information processing. In this study, we consider both self-confidence and information processing as potential mediators of the relationship between anxiety and advice taking.

\section{$\underline{\text { Method }}$}

\section{$\underline{\text { Participants }}$}

One hundred twenty-two students and adults (58 male, $M_{a g e}=32, S D=9.06$ ) from a city in the Northeastern United States participated in the study in exchange for a $\$ 4$ show-up fee and the opportunity to earn an additional $\$ 12$.

\section{Design and Procedure}

Using a between-subjects design, we randomly assigned participants to one of two emotion conditions: anxiety vs. neutral. At the beginning of the experiment, we informed participants that they would complete three unrelated studies that had been combined for the sake of convenience: the "Estimation Study" (which included two parts), the "Vivid Recall Study" (where we introduced our emotion manipulation) and the "Word Recognition Task" (which we used to assess information processing). 
Estimation Study, Part 1: Initial estimates. We told participants that they would be randomly assigned to the role of either adviser or advice recipient, and that another participant would be assigned to the other role. All participants were actually assigned to the role of advice recipient. Across three rounds, participants viewed a photograph of a jar filled with coins and estimated the amount of money in each jar. In both Part 1 (initial estimates) and Part 2 (revised estimates), participants received an additional $\$ 2$ if their estimate fell within 25 cents of the true amount of money in the jar.

Emotion induction. After providing three initial estimates, participants completed a (purportedly unrelated) study, the "Vivid Recall Study," which was actually our emotion manipulation (anxiety vs. neutral). In this study, we used a writing induction. We asked participants to write a short essay. In the neutral condition, the instructions read:

Please take a few minutes to answer the following question as truthfully as possible. Once you've finished, then go on to the next task. Please describe, as best you can, how you typically spend your evenings. You might begin by writing down a detailed description of your activities, and then figure out how much time you devote to each activity. Please write in complete sentences. And, if you can, please write your description so that someone reading this might be able to understand how you typically spend your evenings.

In the anxiety condition, the instructions read:

Please take a few minutes to answer the following question as truthfully as possible. Once you've finished, then go on to the next task. Please describe, as best you can, a situation you experienced in the past that made you feel very anxious. You might begin by writing down a description of your feelings toward someone or something that caused you to feel high levels of anxiety. Then write about the details of such situation/moment. Please write in complete sentences. And, if you can, please write your description so that someone reading this might be able to understand the feelings you had.

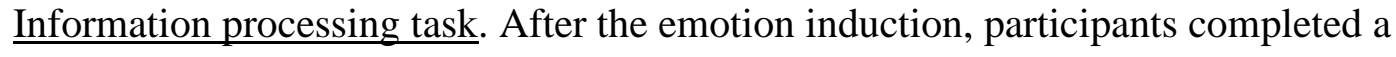
"Word Recognition Task" (i.e., Stroop task to measure information processing) and answered a 
short questionnaire that assessed self-confidence. We counterbalanced the order in which the Stroop task and the questionnaire were presented to participants.

In the Stroop task, we presented participants with the names of different colors. For ten rounds, the color names matched the word (e.g., "RED" was printed in red). For a second set of ten rounds, the color names appeared in colors that did not match the word (e.g., "RED" was printed in yellow). In each round, as soon as the word appeared on the screen, participants were asked to type the color of the text as fast as they could. We recorded the time it took them to type the color of the text in each round. We computed the difference in time between the incongruent and congruent trials and used this difference as an assessment of information processing (DeWall, Baumeister, \& Vohs, 2008; Richeson \& Trawalter, 2005).

Estimation Study, Part 2: Revised estimates. After completing the Stroop task and the questionnaire, we asked participants to re-estimate the amount of money in each of the jars they had seen in Part 1 of the estimation study. This time, however, participants received an estimate from another participant in addition to seeing their own initial estimates from Part 1.

Final questionnaire. Participants completed a final questionnaire with demographic information and a manipulation check. Specifically, we asked participants to think back to the writing task and to indicate the extent to which they felt various emotions.

\section{$\underline{\text { Results }}$}

Emotion Manipulation Check. Feelings of anxiety were higher in the anxiety condition $(M=5.64, S D=2.11)$ than they were in the neutral condition $(M=1.85, S D=1.46), t(120)=11.68$, $p<.001$. Neutral feelings were higher in the neutral condition than they were in the anxiety condition $(M=3.73, S D=1.96$ vs. $M=2.53, S D=1.94, t[120]=3.36, p=.001)$. 
$\underline{\text { Advice Taking. As predicted, results from a repeated-measures ANOVA demonstrated }}$ that advice use in the anxiety condition was significantly higher $(M=0.61, S D=0.37)$ than in the neutral condition $(M=0.36, S D=0.41), F(1,120)=15.66, p<.001, \eta_{p}{ }^{2}=.12$.

Information Processing. We assessed information processing by computing the difference in response time for each participant between the congruent and incongruent words in the Stroop task. Lower scores reflect faster response times and indicate better information processing. Consistent with prior research (e.g., Eysenck et al., 2007), we found that information processing was lower (and changes in the response times were higher) for participants in the anxiety condition than for those in the neutral condition $(8.33 \mathrm{sec}$ on average vs. $3.85 \mathrm{sec}), t(120)=3.77$, $p<.001$.

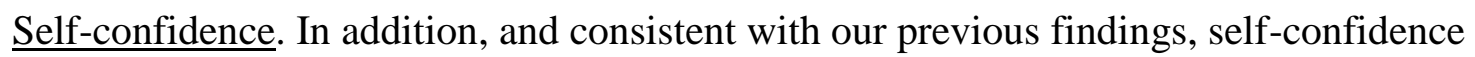
was lower for participants in the anxiety condition $(M=5.23, S D=1.10)$ than it was for those in the neutral condition $(M=5.95, S D=0.92), t(120)=3.95, p<.001$.

Mediation Analysis. We conducted mediation analyses to test whether self-confidence and impaired information processing mediated the effect of anxiety on advice taking. We first considered self-confidence alone as a mediator (see Table 1). When emotion condition and selfconfidence were both entered into a regression model predicting advice taking, the effect of condition was significantly reduced (from $\beta=.34, p<.001$, to $\beta=.18, p<.05 ; 95 \%$ bias-corrected CI, $[.05, .21])$, and self-confidence significantly predicted advice taking $(\beta=-.47, p<.001)$.

Next, we considered impaired information processing as a mediator. Although emotion condition predicted information processing $(\beta=.33, p<.001)$, when we included both emotion condition and information processing in a regression model predicting advice taking, information 
processing did not significantly predict advice taking $(\beta=-.10, p=.29)$. Therefore, the effect of information processing did not mediate the relationship between anxiety and advice taking. ${ }^{3}$

\section{$\underline{\text { Discussion }}$}

In Experiment 4, we consider both impaired information processing and lower selfconfidence as potential mediators of the relationship between anxiety and advice taking. We find that anxiety does impair information processing, but that only diminished self-confidence, not impaired information processing, mediates the link between anxiety and advice taking.

\section{Experiment 5: Anxiety and the Ability to Discern}

In Experiments 5a-c, we extend our investigation of the influence of anxiety on advice taking by exploring the consequences of experiencing low confidence. By harming selfconfidence, anxiety widens an individual's confidence interval around an estimate and expands the range of ideas an individual is likely to consider to be reasonable. As a result, anxious individuals are likely to be more receptive to bad advice than are individuals in a neutral emotional state. Therefore, the relationship we identify linking anxiety and advice taking may present a particularly important problem when advice is bad.

\section{Experiment 5a: Anxiety and the Ability to Perceive Advice Quality}

In Experiment 5a, we examine how anxiety influences perceptions of advice quality.

\section{$\underline{\text { Method }}$}

\section{$\underline{\text { Participants }}$}

We recruited 103 adults from a U.S. representative sample (52 male, $M_{\text {age }}=45, S D=15.95$ ) to participate in an online study in exchange for $\$ 6$.

\section{$\underline{\text { Design and Procedure }}$}

\footnotetext{
${ }^{3}$ We note that when both self-confidence and information-processing were entered into the regression model simultaneously, self-confidence predicted advice taking $(\beta=-.47, p<.001)$ but information processing did not $(\beta=-.10$, $p=.21)$.
} 
We randomly assigned respondents to one of four experimental conditions using a 2 (Emotion: neutral vs. anxiety) x 2 (Advice quality: reasonable vs. unreasonable) betweensubjects design.

We manipulated emotions by asking participants to engage in the same writing task we used in Experiment 4. After the emotion induction, we showed participants three photos of jars filled with coins, one photo at a time. Along with each photo, we showed participants an estimate of the value of money in the jar provided by another participant. We informed participants that the other participant had previously participated in the study in the role of advisor. For each jar, we asked participants to evaluate both how accurate and how reasonable the advisor's estimate was using a 7-point scale (ranging from $1=$ not at all, to $7=$ very much). Responses to the two questions were highly correlated $(r=.86, p<.001)$, and we report averaged responses to these questions.

After the three rounds, we asked participants to think back to the writing task and to indicate the extent to which they felt different emotions.

\section{$\underline{\text { Pilot Study }}$}

Prior to conducting the main study, we conducted a pilot study with a non-overlapping sample of participants $(N=79)$. We asked these participants to view the same three photographs of jars filled with coins and to make estimates that they would offer as advice to future participants. We informed participants that we would pay them for accuracy. We used these data to create two types of advice; we used the mean estimate from the pilot study as the value for "reasonable" advice, and we used the value two standard deviations above the mean as "unreasonable" advice. On average, the reasonable advice was $\$ 2.30$ lower than the true value of 
the money in the jar, and the unreasonable advice as $\$ 5.29$ higher than the true value of the money in the jar.

\section{$\underline{\text { Results and Discussion }}$}

Emotion Manipulation Check. Consistent with our manipulation, self-reported neutral feelings were higher in the neutral condition $(M=4.24, S D=2.20)$ than in the anxiety condition $(M=2.61, S D=1.74), F(1,99)=16.55, p<.001, \eta_{p}{ }^{2}=.14$, and self-reported feelings of anxiety were higher in the anxiety condition $(M=4.66, S D=2.21)$ than in the neutral condition $(M=2.15$, $S D=1.60), F(1,99)=43.62, p<.001, \eta_{p}^{2}=.31$.

Perceived Advice Quality. In each round, we averaged participants' responses to the accuracy and reasonableness questions and used these ratings as a measure of perceived advice quality. A 2 (anxiety vs. neutral) x 2 (reasonable vs. unreasonable advice) repeated-measures between-subjects ANOVA (repeated on round) revealed that participants rated the advice higher on quality in the reasonable-advice condition $(M=5.49, S D=1.27)$ than in the unreasonableadvice condition $(M=4.52, S D=1.34), F(1,99)=21.88, p<.001, \eta_{p}{ }^{2}=.18$.

More interestingly, we found that perceived advice quality was higher in the anxiety condition $(M=5.42, S D=1.28)$ than in the neutral condition $(M=4.66, S D=1.38), F(1,99)=15.55$, $p<.001, \eta_{p}{ }^{2}=.14$. We also found a significant interaction between advice quality and emotion condition, $F(1,99)=11.01, p=.001, \eta_{p}{ }^{2}=.10$. When participants experienced incidental anxiety, we found no significant difference in ratings of perceived advice quality between the reasonable and unreasonable advice $(M=5.56, S D=1.37$ vs. $M=5.29, S D=1.19), F(1,44)<1, p=.40, \eta_{p}{ }^{2}=.02$. When participants were in a neutral state, however, ratings of perceived advice quality were higher in the reasonable-advice condition $(M=5.44, S D=1.21)$ than they were in the unreasonable-advice condition $(M=3.86, S D=1.05), F(1,55)=41.69, p<.001, \eta_{p}{ }^{2}=.43$ (see Figure 2$)$. 
Overall, these results suggest that, compared to participants in the neutral condition, participants in the anxiety condition are less discerning between good and bad advice.

\section{Experiment 5b: Anxiety and Receptivity to Bad Advice}

In Experiment 5a, we focused on the relationship between anxiety and perceived advice quality. In Experiment 5b, we explore how anxiety influences advice taking when advice is poor.

\section{$\underline{\text { Method }}$}

\section{$\underline{\text { Participants }}$}

One hundred eighty-nine students (118 female, $\left.M_{a g e}=21, S D=2.29\right)$ at a university in the Southern United States participated in the study in exchange for a $\$ 2$ show-up fee and the opportunity to earn an additional \$6.

\section{$\underline{\text { Design and Procedure }}$}

We randomly assigned participants to one of six experimental conditions using a 2 (Emotion: neutral vs. anxiety) x 3 (Advice quality: reasonable vs. unreasonably high vs. unreasonably low) between-subjects design.

As in Experiment 4, we manipulated emotions with a writing task and we asked participants to estimate the value of jars filled with coins. In Part 1 and Part 2 of the estimation task, participants received an additional \$1 if an estimate fell within 25 cents of the true amount in the jar.

To manipulate advice quality, we used the same "reasonable" advice values as those we used in Experiment 5a. In this study, we included both "unreasonably high" advice, or the value two standard deviations above the reasonable value in the pilot study (on average, $\$ 5.29$ above the true value of the jar), and "unreasonably low" advice, or the value two standard deviations below the reasonable value in the pilot study (on average, $\$ 9.90$ below the true value of the jar). 
Our primary dependent measure was weight of advice. As in our other studies, we measured emotion, self-confidence, and demographics.

\section{$\underline{\text { Results and Discussion }}$}

Emotion Manipulation Check. Neutral feelings $(\alpha=.84)$ were higher in the neutral condition than they were in the anxiety condition $(M=4.66, S D=2.20$ vs. $M=3.09, S D=2.03)$, $F(1,183)=25.74, p<.001, \eta_{p}{ }^{2}=.12$, and feelings of anxiety $(\alpha=.92)$ were higher in the anxiety condition than they were in the neutral condition $(M=4.45, S D=2.23$ vs. $M=1.92, S D=1.49)$, $F(1,183)=79.61, p<.001, \eta_{p}^{2}=.30$.

Advice-taking. We conducted a 2 (anxiety vs. neutral) x 3 (reasonable vs. unreasonably high vs. unreasonably low advice) repeated-measures between-subjects ANOVA (repeated measure on round). We found that anxiety significantly influenced advice-taking, $F(1,183)=58.41, p<.001, \eta_{p}{ }^{2}=.24$. The effect of advice quality was not significant, $F(2,183)=1.85, p=.16, \eta_{p}{ }^{2}=.02$, but the interaction term was marginally significant, $F(2,183)=2.56, p=.08, \eta_{p}{ }^{2}=.03$.

In the neutral condition, advice use differed across advice quality $(F[2,85]=4.70, p<.02$, $\left.\eta_{p}{ }^{2}=.10\right)$. Participants in the neutral condition were less receptive to unreasonably high and unreasonably low advice than they were to reasonable advice. Participants in the anxiety condition, however, were not less receptive to unreasonable advice than they were to reasonable advice $\left(F[2,98]<1, p=.93, \eta_{p}{ }^{2}=.001\right)$. We depict these results in Figure 3.

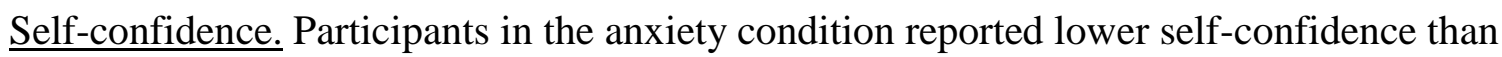
did participants in the neutral condition $(M=4.75, S D=1.76$ vs. $M=5.95, S D=1.44$; $\left.F[1,183]=27.29, p<.001, \eta_{p}^{2}=.13\right)$. Advice quality did not influence self-confidence. 
We next tested for self-confidence as a mediator (see Table 1). The effect of anxiety on advice use was significantly reduced when we included self-confidence in the equation (95\% bias-corrected CI, $[.13, .27])$, and self-confidence significantly predicted advice taking. These results further demonstrate that self-confidence mediates the effect of incidental anxiety on advice taking.

Although participants in the neutral condition were able to discriminate between good and bad advice, discounting both unreasonably high and low advice, participants in the anxiety condition did not.

\section{Experiment 5c: Anxiety and an Advisor's Accuracy}

In Experiments 5a-5b, we found that anxiety impairs the ability to discriminate between good and bad advice. In Experiment 5c, we explore this relationship in a different way by explicitly manipulating the historical accuracy of the advisor.

\section{$\underline{\text { Method }}$}

\section{$\underline{\text { Participants }}$}

One hundred eighteen students (48 male, $M_{a g e}=20.89, S D=2.18$ ) at a university in the northeastern United States participated in the study in exchange for a \$2 show-up fee and the opportunity to earn an additional $\$ 6$.

\section{$\underline{\text { Design and Procedure }}$}

We randomly assigned participants to one of four experimental conditions using a 2 (Emotion: neutral vs. anxiety) x 2 (Advisor accuracy: accurate vs. less accurate) betweensubjects design. We used the same estimation task (jar of coins) and the same emotion induction (writing task) as we did in Experiment 5b. 
For the second part of the estimation task, we informed participants that they would receive advice from an individual who had made estimates in a prior study and was paid based on accuracy. In the accurate-advisor condition, we told participants that the advisor's prior estimates were accurate $80 \%$ of the time. That is, the advisor had given an estimate within $\$ 0.25$ of the true value $80 \%$ of the time. In the less-accurate advisor condition, we told participants that the advisor's prior estimates were accurate $50 \%$ of the time. In reality, the advice values did not differ across conditions.

When participants received the advisor's estimates, they evaluated how accurate and reasonable they perceived the estimates to be (from $1=$ not at all, to $7=$ very much). We combined these two items to measure perceived advice quality (average $\alpha$ across rounds $=.91$ ).

\section{$\underline{\text { Results }}$}

Emotion Manipulation Check. Consistent with our manipulation, neutral feelings were higher in the neutral condition than in the anxiety condition $(M=4.69, S D=2.09$ vs. $M=3.02$, $S D=2.03), F(1,114)=19.54, p<.001, \eta_{p}{ }^{2}=.15$, and feelings of anxiety were higher in the anxiety condition than in the neutral condition $(M=4.33, S D=2.37$ vs. $M=2.02, S D=1.67)$, $F(1,114)=36.78, p<.001, \eta_{p}^{2}=.24$.

Advice taking. We conducted a 2 (emotion) x 2 (advisor accuracy) repeated-measures between-subjects ANOVA (repeated measure on round) with advice use as the dependent variable. We found that anxiety significantly increased advice taking, $F(1,114)=30.25, p<.001$, $\eta_{p}{ }^{2}=.21$. The effect of advisor accuracy was not significant, $F(1,114)=2.39, p=.13, \eta_{p}{ }^{2}=.02$, but the interaction was, $F(1,114)=4.38, p<.05, \eta_{p}{ }^{2}=.04$. In the neutral condition, participants were less receptive to advice in the less-accurate advisor condition than they were in the accurateadvisor condition $\left(M_{W O A}=0.11, S D=0.24\right.$ and $M_{W O A}=0.34, S D=0.38$, respectively), $F(1,56)=8.36$, 
$p<.01, \eta_{p}{ }^{2}=.13$. Participants in the anxiety condition, however, were not less receptive to advice based on advisor accuracy $\left(M_{W O A}=0.60, S D=0.42\right.$ and $M_{W O A}=0.56, S D=0.38$, respectively).

Perceived Advice Quality. We conducted the same analysis using perceived advice quality as the dependent variable. As expected, participants rated advice quality to be higher in the accurate-advisor condition $(M=5.49, S D=1.19)$ than they did in the less-accurate advisor condition $(M=4.66, S D=1.34), F(1,114)=23.68, p<.001, \eta_{p}{ }^{2}=.17$. On average, participants rated the estimates as more accurate and reasonable in the anxiety condition $(M=5.47, S D=1.13)$ than they did in the neutral condition $(M=4.62, S D=1.39), F(1,114)=22.74, p<.001, \eta_{p}{ }^{2}=.17$.

Interestingly, we found a significant interaction between advisor accuracy and the emotion condition, $F(1,114)=17.75, p<.001, \eta_{p}{ }^{2}=.14$. When participants experienced neutral feelings, they perceived the advice to be more accurate in the accurate-advisor condition $(M=5.44, S D=1.15)$ than in the less-accurate advisor condition $(M=3.80, S D=1.09)$, $F(1,56)=42.22, p<.001, \eta_{p}{ }^{2}=.43$. However, when participants felt anxious, they perceived the advice to be similarly accurate across the two conditions $(M=5.54, S D=1.24$ vs. $M=5.42$, $S D=1.05), F(1,58)<1, p=.65, \eta_{p}^{2}=.004$.

Self-confidence. A 2 (emotions) x 2 (advisor accuracy) between-subjects ANOVA with self-confidence as the dependent variable revealed that participants in the anxiety condition reported lower self-confidence than did participants in the neutral condition $(M=4.65, S D=1.84$ vs. $M=5.78, S D=1.57), F(1,114)=13.08, p<.001, \eta_{p}{ }^{2}=.10$. We found no other significant effect (both $p$ 's >.16). Importantly, self-confidence mediated the relationship between anxiety and advice taking (95\% bias-corrected CI, $[.07, .25])$, as well as the relationship between anxiety and perceived advice quality (95\% bias-corrected CI, $[.03, .31])$, as summarized in Table 1.

\section{$\underline{\text { Discussion }}$}


In Experiment 5c, we manipulate the purported accuracy of the advisor and find that anxiety increases reliance upon advice from both very accurate and less accurate advisors. Consistent with our findings in Experiments 5a and 5b, anxious participants are less discerning than participants in a neutral state. Participants in the neutral condition rely more heavily on advice when the advisor is purportedly very accurate than when the advisor is purportedly less accurate. Anxious participants, however, rely heavily on advice from both types of advisors.

\section{Experiment 6: Anxiety and Biased Advisors}

In Experiment 6, we examine the influence of anxiety on advice taking when advisees know that advisors have a conflict of interest. Since anxious individuals are less discerning than those in a neutral emotional state, they may be particularly susceptible to biased advice from advisors with a disclosed conflict of interest.

\section{$\underline{\text { Method }}$}

\section{$\underline{\text { Participants }}$}

One hundred thirty-nine college students ( 81 male, $M_{a g e}=20, S D=0.66$ ) at a university in the southeastern United States participated in the study in exchange for a $\$ 2$ show-up fee and the opportunity to earn an additional $\$ 6$.

\section{Design and Procedure}

We randomly assigned participants to one of four experimental conditions using a 2 (Emotion: neutral vs. anxiety) x 2 (Advisor conflict: conflict of interest vs. no conflict of interest) between-subjects design. We used a procedure very similar to the one we used in Experiments 4-5.

For the estimation task, we told participants, "You will be randomly assigned to the role of either advisor or advice recipient. Another person in the room will be assigned to the other 
role." In reality, every participant was assigned to the role of advice recipient. We also informed participants that they would receive a bonus for the accuracy of their estimates; specifically, we told them that they would earn a $\$ 1$ bonus every time one of their estimates was within 25 cents of the true amount.

For the revised estimates, we used the same values as in the reasonable advice condition in Experiments 5a and 5b. Before receiving advice, we told participants that their advisor had an informational advantage. Specifically, we informed participants that the advisor had been given additional information about the range of values for each jar. In addition, we adapted Cain et al.'s (2005) conflict of interest disclosure for our manipulation. Each participant read one of two conflict of interest disclosures. In the conflict of interest condition, the instructions read:

Your advisor's payment depends on how much your estimate exceeds the value of the coins in the jar. In particular, in each round, the advisor will receive $\$ 1$ for every 25 cents your estimate exceeds the actual value of the jar of coins.

In the no conflict of interest condition, the instructions read:

Your advisor's payment depends on how accurate you are in estimating the value of the coins in the jar. In particular, in each round, the advisor will receive $\$ 1$ every time your estimate is within 25 cents of the actual value of the jar of coins.

\section{$\underline{\text { Results }}$}

Emotion Manipulation Check. Consistent with our manipulation, participants reported higher neutral feelings in the neutral condition $(M=5.72, S D=2.06)$ than they did in the anxiety condition $(M=3.62, S D=2.20), F(1,135)=34.42, p<.001, \eta_{p}{ }^{2}=.20$, and they reported higher anxiety in the anxiety condition $(M=4.46, S D=2.42)$ than they did in the neutral condition $(M=2.06$, $S D=1.55), F(1,135)=48.29, p<.001, \eta_{p}{ }^{2}=.26$.

Advice Taking. We conducted a 2 (emotion) x 2 (advisor conflict) repeated-measures between-subjects ANOVA (repeated measure on round) with advice use as the dependent 
variable. Advice taking was higher in the anxiety condition than in the neutral condition $\left(M_{W O A}=0.60\right.$ vs. 0.24$), F(1,135)=35.19, p<.001, \eta_{p}{ }^{2}=.21$. The main effect of conflict of interest was not significant, $F(1,135)=1.62, p=.21, \eta_{p}{ }^{2}=.01$, and the interaction was marginally significant, $F(1,135)=3.38, p<.07, \eta_{p}^{2}=.02$.

We hypothesized that, compared to individuals in a neutral emotional state, individuals experiencing anxiety would fail to discount advice from advisors with a conflict of interest. The results are directionally consistent with this hypothesis. Participants who felt anxious weighed advice similarly when their advisor did and did not have a conflict of interest $\left(M_{W O A}=0.61 \mathrm{vs}\right.$. $0.58), F(1,68)<1, p=.70, \eta_{p}{ }^{2}=.002$. In contrast, participants in the neutral condition discounted the advice significantly more from an advisor with a conflict of interest than from an advisor without a conflict of interest $\left(M_{W O A}=0.15\right.$ vs. 0.34$), F(1,67)=5.06, p<.03, \eta_{p}{ }^{2}=.07$. We depict this pattern of results in Figure 4.

In this experiment, participants knew that advisors with a conflict of interest earned money when their revised estimates were higher than the true value of the jar. Thus, we examine weight of advice measures for participants whose initial estimates were lower than the advice value. We find that anxiety significantly increased advice taking, $F(1,72)=12.35, p=.001$, $\eta_{p}{ }^{2}=.15$. The main effect of conflict of interest was not significant, $F(1,72)=1.77, p=.19, \eta_{p}{ }^{2}=.02$, but the interaction was, $F(1,72)=4.16, p<.05, \eta_{p}{ }^{2}=.06$. The presence of a conflict of interest did not affect the extent to which anxious participants were receptive to the advice $\left(M_{W O A}=0.52\right.$ with a conflict of interest vs. 0.47 without a conflict of interest; $p=.62$ ), but it did influence the extent to which participants in the neutral condition discounted the advice. Specifically, participants in the neutral condition discounted advice from an advisor with a conflict of interest more than they 
discounted advice from an advisor without a conflict of interest $\left(M_{W O A}=0.10\right.$ vs. 0.36$)$, $F(1,29)=6.75, p<.02, \eta_{p}^{2}=.19$.

Self-confidence. Self-confidence $(\alpha=.81)$ varied by condition $(F[1,135]=14.06, p<.001$, $\left.\eta_{p}{ }^{2}=.09\right)$. Participants in the anxiety condition reported lower self-confidence than did those in the neutral condition $(M=5.48, S D=0.79$ vs. $M=5.96, S D=0.68)$. The conflict of interest manipulation did not influence self-confidence, and we found no interaction between the conflict of interest manipulation and the emotion condition on self-confidence.

We also tested whether self-confidence mediated the relationship between anxiety and advice taking and found evidence for mediation (see Table 1).

\section{$\underline{\text { Discussion }}$}

As we found in Experiments 1-5, compared to individuals in a neutral emotional state, anxious individuals are more receptive to advice and self-confidence mediates this relationship. In this final experiment, we examine a particular case of bad advice: when advisors have a conflict of interest. We find that anxious individuals remain very receptive to advice, even when their advisor has a disclosed conflict of interest.

\section{General Discussion}

Across eight experiments, we document a robust relationship between anxiety and receptivity to advice. Compared to people in a neutral emotional state, people who feel anxious are more likely to seek advice and are more likely to rely on the advice they receive. This pattern of results does not generalize to other negatively-valenced emotions, such as anger.

Consistent with prior research (e.g., Eysenck, 1992), we find that anxiety impairs information processing. The relationship between anxiety and advice taking, however, is not mediated by impaired information processing; rather, it is mediated by reduced self-confidence. 
Anxiety lowers self-confidence, which, in turn, increases advice seeking and reliance upon advice (see Figure 1). Our results also demonstrate that anxiety impairs the ability to discriminate between reasonable and unreasonable advice. Anxious individuals rely heavily on advice, even when the advice is bad and advisors have a conflict of interest.

Across our studies, we employed different emotion inductions and different decision tasks. We examined both advice taking and the relatively understudied decision to seek advice. In our studies, we manipulated incidental anxiety, which offered a conservative test of the relationship between anxiety and advice taking. In practice, decision makers are likely to be influenced not only by incidental anxiety from an unrelated and irrelevant source, but also by directed anxiety triggered by the decision domain itself (e.g., choosing a surgery option in a hospital setting) and by other people (e.g., a realtor who may induce anxiety while recommending a purchase price for a house).

Prescriptively, our findings highlight the importance of assessing advice quality, especially when individuals are anxious. Though individuals in a neutral emotional state were able to discern good advice from bad advice, anxious individuals were less discerning and very receptive to extreme values and bad advice. Our findings underscore the importance of assessing advice quality in general, but when individuals are anxious in particular. Theoretical Implications

Our findings extend our understanding of the influence of anxiety on cognition and motivation. Prior work has found that anxiety impairs cognitive performance (e.g., Eysenck, 1982; Sengupta \& Johar, 2001). Our work demonstrates that anxiety also influences motivation. By eroding self-confidence, anxiety motivates individuals to reduce uncertainty and both to seek 
and to rely on advice from others. Future research should extend our investigation to study both cognitive and motivational consequences of experiencing incidental and integral emotions.

Our findings also deepen our understanding of the advice process. We document the influence of anxiety, we consider the influence of bad and biased advice, and we investigate the decision to seek advice as well as the decision to take advice. Rather than making decisions in isolation, individuals often make decisions after receiving input from others. This is especially true for exactly the types of decisions that are likely to trigger anxiety-important and novel domains that have the potential for adverse consequences.

In our investigation, we devoted particular attention to conditions under which advice taking may harm decision making. By considering contexts in which advice is bad and advisors have a conflict of interest, we identified systematic ways in which advice taking may harm individuals' decisions. Further, we studied both the decision to take advice and the decision to seek advice. A growing literature has begun to study how people integrate the information they receive from others (Bonaccio \& Dalal, 2006; Larrick \& Soll, 2006). Very little work, however, has investigated the critical precursor to that process: the decision to seek advice.

Finally, our work contributes to extant research highlighting the importance of emotions in interpersonal and organizational settings (e.g., Ashforth \& Humphrey, 1995; Ashkanasy, Härtel, \& Zerbe, 2000; Brief \& Weiss, 2002; Fineman, 1993; Fisher \& Ashkanasy, 2000; Judge \& Ilies, 2004). Many organizational settings induce stress (e.g., Cannon-Bowers \& Salas, 1998; Driskell \& Salas, 1996) and anxiety (D’Aveni, 1995; Hartley et al., 1991; Jordan, Ashkanasy, \& Härtel, 2002), but little prior research has studied how anxiety might influence organizationally relevant decision making, such as reliance upon advice from peers and managers.

\section{$\underline{\text { Limitations and Future Directions }}$}


The contribution of our work is qualified by limitations of our investigation. We identify these as both limitations and opportunities for future research. Across our studies, advisors and decision makers never met face-to-face. Although this approach afforded us experimental control, future work could examine the influence of anxiety on the advice process in face-to-face encounters.

In our studies, we considered contexts in which advice is poor and when advisors have a conflict of interest. Future work could further explore these domains to develop our understanding of when advice systematically harms decision making. Specifically, this work could identify strategies for curtailing the effects of harmful advice. For example, anxious individuals who are particularly prone to bad advice may become less receptive to poor advice if they recognize and regulate their emotions.

Another limitation of the present work is the use of tasks that required a judgment or a solution to a problem that may not have been highly self-relevant to participants. Often, we consult others for their opinion when facing decisions that are important to us such as choosing a career or a medical treatment. Future research could extend our investigation by employing tasks that are high in self-relevance. Quite possibly, self-relevance may exacerbate the influence of anxiety on advice seeking and advice-taking.

Future work should also examine the interpersonal consequences of feeling anxious. For example, researchers could investigate whether feeling or expressing anxiety influences trust and liking as well as how anxiety spreads between individuals and within groups. Anxiety increases the need for social affiliation (Schachter, 1959; Taylor, 2006), a need that may manifest itself as a desire to seek and overvalue information from others. 
Many open questions remain with respect to the broader influence of anxiety on behavior. For example, small amounts of anxiety may be very constructive. Norem and Chang (2002) found that a small amount of anxiety causes people to prepare more thoroughly in advance of anxiety-inducing events. In other work, Alter et al. (2010) found that reappraising feelings of anxiety as excitement (i.e., reframing threats as challenges) can both improve motivation and diminish stereotype threat. Quite possibly, both the magnitude and timing of anxious feelings moderate the influence of anxiety on behavior.

Overall, our findings describe robust relationships between anxiety and advice seeking and between anxiety and advice taking. Anxiety erodes self-confidence and causes individuals to seek advice from others and to be less discriminating between good and bad advice. Informed by these findings, we conclude by offering our own advice to anyone who might be anxious: be wary of an advisor's conflict of interest and be particularly vigilant about the quality of the advice you receive. 


\section{References}

Alter, A., Aronson, J., Darley, J., Rodriguez, C., \& Ruble, D. (2010) Rising to the threat: Reducing stereotype threat by reframing the threat as a challenge, Journal of Experimental Social Psychology, 46(1), 166-171.

Ashforth, B. E., \& Humphrey, R. H. (1995). Emotion in the workplace: A reappraisal. Human Relations, 48, 97-125.

Ashkanasy, N. M., Härtel, C. E. J., \& Zerbe, W. J. (2000). Emotions in the workplace: Research, theory, and practice - Introduction. In N. M. Ashkanasy, W. Zerbe, \& C.E.J. Härtel (Eds.) Emotions in the workplace: Research, theory, and practice (pp. 3-18). Westport, CT: Quorum Books.

Bandura, A. (1977). Self-efficacy: Toward a unifying theory of behavioral change. Psychological Review, 84, 191-215.

Bandura, A. (1986). Social foundations of thought and action: A social cognitive theory. Englewood Cliffs, NJ: Prentice Hall.

Bandura, A. (1997). Self-efficacy: The exercise of control. New York: Freeman.

Barlow, D. H. (1988). Anxiety and its disorders: The nature and treatment of anxiety and panic. New York: Guilford Press.

Baron, R. M., \& Kenny, D. A. (1986). The moderator-mediator variable distinction in social psychological research: Conceptual, strategic and statistical considerations. Journal of Personality and Social Psychology, 51, 1173-1182.

Beal, D. J., Weiss, H. M., Barros, E., \& MacDermid, S. M. (2005). An episodic process model of affective influences on performance. Journal of Applied Psychology, 90, 1054-1068. 
Bonaccio, S., \& Dalal, R. S. (2006). Advice taking and advice giving in decision making: an integrative literature review, and implications for the organizational sciences. Organizational Behavior and Human Decision Processes, 101, 127-151.

Brief, A. P. \& Weiss, H. M. (2002). Organizational behavior: Affect in the workplace. Annual Review of Psychology, 53, 279-307.

Brooks, A. W., \& Schweitzer, M. (2011). Can nervous Nelly negotiate? How anxiety causes negotiators to make low first offers, exit early, and earn less profit. Organizational Behavior and Human Decision Processes, 115, 43-54.

Butler, G., \& Mathews, A. (1983). Cognitive processes in anxiety. Advances in Behaviour Research \& Therapy, 5, 51-62.

Butler, G., \& Mathews, A. (1987). Anticipatory anxiety and risk prediction. Cognitive Therapy and Research, 11, 551-565.

Cain, D., Loewenstein, G., Moore, D. (2011), When sunlight fails to disinfect: Understanding the perverse effects of disclosing conflicts of interest, Journal of Consumer Research, 37, 836-857.

Cain, D. M., Loewenstein, G., \& Moore, D. A. (2005). The dirt on coming clean: Perverse effects of disclosing conflicts of interest. Journal of Legal Studies, 34, 1-25.

Cannon-Bowers, J.A., \& Salas, E. (1998). Making decisions under stress. Washington, D.C.: American Psychological Association.

Chen, E. (1996). Effects of state anxiety on selective processing of threatening information. Cognition \& Emotion, 10(3), 225-240.

Clore, G.L., Gasper, K., \& Garvin, E. (1998). Affect as Information. In J.P. Forgas (Ed.), Handbook of affect and social cognition, pp. 121-144. Mahwah, NJ: Erlbaum. 
Cooper, R.S. (1991). Information processing in the judge-advisor system of group decisionmaking. Unpublished master's thesis, University of Illinois, Urbana-Champaign.

Darke, S. (1988). Effects of anxiety on inferential reasoning task performance. Journal of Personality and Social Psychology, 55(3), 499-505.

Deffenbacher, J. L. (1977). Relationship of worry and emotionality to performance on the Miller analogies test. Journal of Educational Psychology, 69, 191-195.

DeWall, C. N., Baumeister, R. F., \& Vohs, K. D. (2008). Satiated with belongingness? Effects of acceptance, rejection, and task framing on self-regulatory performance. Journal of Personality and Social Psychology, 95(6), 1367-1382.

D’Aveni, R. A. (1995). Hypercompetition. New York: Free Press.

Driskell, J. E., \& Salas, E. (1996). Stress and human performance. Mahwah, NJ: L. Erlbaum.

Dunn, J., Ruedy, N. \& Schweitzer, M. (2011). Too good to be trusted? The effect of performance comparisons on affective and cognitive trust. Organizational Behavior and Human Decision Processes.

Dunn, J. \& Schweitzer, M. (2005). Feeling and believing: The influence of emotion on trust. Journal of Personality and Social Psychology, 88(6), 736-748.

Endler, N. S. (1980). Person-situation interaction and anxiety. In I. L. Kutash \& L. B. Schlesinger (Eds.). Handbook on stress and anxiety. Contemporary knowledge, theory and treatment (pp. 241-266).

Eysenck, M. W. (1979). Anxiety, learning, and memory: A reconceptualization. Journal of Research in Personality, 13, 363-385.

Eysenck, M. W. (1982). Attention and arousal, cognition and performance. Berlin, Germany: Springer-Verlag. 
Eysenck, M.W. (1992). Anxiety: The Cognitive Perspective. London: Erlbaum.

Eysenck, M.W. (1997). Eysenck, M.W. Anxiety and cognitive processes. In C.Cooper \& V. Varma (Eds.), Processes in Individual Differences. London: Routledge.

Eysenck, M.W., Derakshan, N., Santos, R., \& Calvo, M. (2007). Anxiety and cognitive performance: The Attentional Control Theory. Emotion, 7 (2), 336 - 353.

Feng, B., \& MacGeorge, E. L. (2006). Predicting receptiveness to advice: Characteristics of the problem, the advice-giver, and the recipient. Southern Journal of Communication, 71(1), $67-85$.

Fineman, S. (1993). Organizations as emotional arenas. In S. Fineman, (Ed.), Emotion in organizations (pp. 9-35). London, UK: Sage Publications.

Fisher, C. D., \& Ashkanasy, N. M. (2000). The emerging role of emotions in working life: An introduction. Journal of Organizational Behavior, 21, 123-129.

Forgas, J. P. (1995). Mood and judgment: The Affect Infusion Model (AIM). Psychological Bulletin, 11, 39-66.

Fredrickson, B. L. \& Branigan, C. (2005). Positive emotions broaden the scope of attention and thought-action repertoires. Cognition and Emotion, 19(3), 313-332.

Frijda, N. H. (1986). The emotions. Cambridge: Cambridge Univ. Press.

Frijda, N. H., Kuipers,P.,\& ter Shure, E. (1989). Relations among emotion, appraisal, and emotional action readiness. Journal of Personality and Social Psychology, 57, 212-228.

Gallagher, D., \& Clore, G. (1985). Effects of fear and anger on judgments of risk and evaluations of blame. Paper presented at the meeting of the Midwestern Psychological Association, Chicago. 
Ganzer, V. J. (1968). Effects of audience presence and test anxiety on learning and retention in a serial learning situation. Journal of Personality and Social Psychology, 8, 194-199.

George, J. M., Jones, G. R., \& Gonzalez, J. A. (1998). The role of affect in cross-cultural negotiations. Journal of International Business Studies, 29, 749-772.

Gino, F. (2008). Do we listen to advice just because we paid for it? The impact of cost of advice on its use. Organizational Behavior and Human Decision Processes, 107(2), 234-245.

Gino, F., \& Moore, D. A. (2007). Effects of task difficulty on use of advice. Journal of Behavioral Decision Making, 20(1), 21-35.

Gino, F., \& Schweitzer, M. (2008). Blinded by anger or feeling the love: How emotions influence advice taking. Journal of Applied Psychology, 93(5), 1165-1173.

Goldsmith, D.J., \& Fitch, K. (1997). The normative context of advice as social support. Human Communication Research, 23, 454-476.

Gould, D., Petlichkoff, L., \& Weinberg, R.S. (1984). Antecedents of, temporal changes in, and relationships between CSAI-2 subcomponents. Journal of Sport Psychology, 6, 289-304.

Grandey A. A. (2000). Emotion regulation in the workplace: A new way to conceptualize emotional labor. Journal of Occupational Health Psychology, 5(1), 95-110.

Gray, J. (1991). Fear, panic, and anxiety: What's in a name? Psychological Inquiry, 2(1), 77-78.

Gross, J. J., \& Levenson, R. W. (1995). Emotion elicitation using films. Cognition \& Emotion, 9 , $87-108$.

Hamilton, V. (1975). Socialization anxiety and information processing: A capacity model of anxiety-induced deficits. In I. Sarason \& C. D. Spielberger (Eds.), Stress and Anxiety, Vol. 2. London: Academic Press. 
Hartley, J., Jacobson, D., Klandermans, P. G., \& Van Vuuren, C.V. (1991). Job insecurity: Coping with jobs at risk. London, UK: Sage Publications.

Harvey, N., \& Fischer, I. (1997). Taking advice: Accepting help, improving judgment, and sharing responsibility. Organizational Behavior and Human Decision Processes, 70, 117133.

Izard, C. E. (1977). Human emotions. New York: Plenum.

Jordan, P. J., Ashkanasy, N. M., \& Härtel, C. E. J. (2002). Emotional intelligence as a moderator of emotional and behavioral reactions to job insecurity. Academy of Management Review, 27, 361-372.

Judge, T. A., \& Ilies, R. (2004). Affect and job satisfaction: A study of their relationship at work and at home. Journal of Applied Psychology, 89(4), 661-673.

Kantor, L., Endler, N., Heslegrave, R., \& Kocovski, N. (2001). Validating self-report measures of state and trait anxiety against a physiological measure. Current Psychology, 20, 3, 207-215.

Larrick, R. P., \& Soll, J. B. (2006). Intuitions about combining opinions: Misappreciation of the averaging principle. Management Science, 52, 111-127.

Lerner J. S., \& Keltner, D. (2001). Fear, anger, and risk. Journal of Personality and Social Psychology, 81(1), 146-159.

Lerner, J. S., \& Keltner, D. (2000). Beyond valence: Toward a model of emotion-specific influences on judgment and choice. Cognition and Emotion, 14, 473-493.

Lerner, J. S., Small, D. A., Loewenstein, G. (2004). Heart strings and purse strings: Carryover effects of emotions on economic decisions. Psychological Science, 15(5), 337-340. 
MacKinnon, D. P., \& Dwyer, J. H. (1993). Estimating mediated effects in prevention studies. Evaluation Review, 17, 144-158.

MacKinnon, D. P., Fairchild, A. J., \& Fritz, M. S. (2007). Mediation analysis. Annual Review of Psychology, 58, 593-614.

Maddux, J. E. (1995). Self-efficacy theory: An introduction. In J.E. Maddux (Ed.), Self-efficacy, adaptation, and adjustment: Theory, research, and application (pp. 3-33). New York: Plenum.

Marks, I. \& Nesse, R. (1994). Fear and fitness: An evolutionary analysis of anxiety. in The Maladapted Mind, New York, NY: Elsevier Science Inc., pp. 57-60.

Martens, R., Burton, D., Vealey, R.S., Bump, L.A., \& Smith, D.E. (1990). Development and validation of the Competitive State Anxiety Inventory-2. In R. Martens, R.S. Vealey, \& D. Burton (Eds.), Competitive anxiety in sport (pp. 117-190). Champaign, IL: Human Kinetics.

Martin, J. J., \& Gill, D. L. (1991). The relationship among competitive orientation, sportconfidence, self-efficacy, anxiety, and performance. Journal of Sport and Exercise Psychology, 13, 149-159.

Moran, S. \& Schweitzer, M. (2008). When better is worse: Envy and the use of deception in negotiations. Negotiation and Conflict Management Research, 1(1), 3-29.

Mueller, J. H. (1976). Anxiety and cue utilization in human learning and memory. In Zuckerman, M. \& Spielberger, C.D. (Eds.) Emotions and Anxiety: New Concepts, Methods and Applications, Potomac, Md: Erlbaum Associates.

Norem, J. \& Chang, E. (2002) The positive psychology of negative thinking, Journal of Clinical Psychology, 58(9), 993-1001. 
Patt, A., Bowles, H. R., \& Cash, D. (2006). Mechanisms for enhancing the credibility of an advisor: Prepayment and aligned incentives. Journal of Behavioral Decision Making, 19, $347-359$.

Pham, M. T. (1998). Representativeness, relevance, and the use of feelings in decision-making. Journal of Consumer Research, 25, 144-159.

Pham, M. T. (2004). The logic of feeling. Journal of Consumer Psychology, 14(4), 360-69.

Raghunathan, R. \& Pham, M. (1999). All negative moods are not equal: Motivational influences of anxiety and sadness on decision making. Organizational Behavior and Human Decision Processes, 79, 1, 56-77.

Raghunathan, R., Pham, M. T., \& Corfman, K. P. (2006). Informational properties of anxiety and sadness, and displaced coping. Journal of Consumer Research, 32(4), 596-601.

Richeson, J.A. \& Trawalter, S. (2005). Why do interracial interactions impair executive function? A resource depletion account. Journal of Personality and Social Psychology, 88, 934-947.

Russell, J. (1980). A circumplex model of affect. Journal of Personality and Social Psychology, $39,6,1161-1178$.

Savitsky, K., Medvec, V. H., Charlton, A. E., \& Gilovich, T. (1998). “What, me worry?' : Arousal, misattribution, and the effect of temporal distance on confidence. Personality and Social Psychology Bulletin, 24, 529-536.

Schunk, D. H. (1995). Self-efficacy and education and instruction. In J. E. Maddux (Ed.), Selfefficacy, adaptation, and adjustment: Theory, research, and application, (pp. 281-303). New York: Plenum. 
Schwarz, N. (1990). Feelings as information: Informational and motivational functions of affective states. In E. Higgins \& R. Sorrentino (Eds.), Handbook of motivation and cognition: Foundations of social behavior. New York: Guilford Press.

Schwarz, N., \& Clore, G. L. (1988). How do I feel about it? Informative functions of affective states. In K. Fiedler \& J. Forgas (Eds.), Affect, cognition, and social behavior (pp. 4462). Toronto, Ontario, Canada: Hogrefe.

Schwarz, N., \& Clore, G. L. (1983). Mood, misattribution, and judgments of well-being: Informative and directive functions of affective states. Journal of Personality and Social Psychology, 45, 513-523.

Schwarzer, R., \& Jerusalem, M. (1995). Generalized self-efficacy scale. In J. Weinman, S. Wright, \& M. Johnston (Eds.). Measures in health psychology: A user's portfolio. Causal and control beliefs (pp. 35-37). Windsor, UK: Nelson.

Sengupta, J., \& Johar, G. V. (2001). Contingent effects of anxiety on message elaboration and persuasion. Personality and Social Psychology Bulletin, 27(February), 139-150.

Shepperd, J., Grace, J., Cole, L., \& Klein, C. (2005). Anxiety and outcome predictions. Personality and Social Psychology Bulletin, 31(2), 267-275.

Smith, C. \& Ellsworth, P. (1985). Patterns of cognitive appraisal in emotion. Journal of Personality and Social Psychology, 48(4), 813-838.

Sniezek, J. A., \& Buckley, T. (1995). Cueing and cognitive conflict in judge-advisor decision making. Organizational Behavior and Human Decision Processes, 62, 159-174.

Sniezek, J. A., \& Van Swol, L. M. (2001). Trust, confidence, and expertise in a judge-advisor system. Organizational Behavior and Human Decision Processes, 84, 288-307. 
Sniezek, J.A., Schrah, G.E., \& Dalal, R.S. (2004). Improving judgment with prepaid expert advice. Journal of Behavioral Decision Making, 17, 173-190.

Spielberger, C. D. (1985). Anxiety, cognition and affect: A state-trait perspective. In A. H. Tuna and J. D. Maser (Eds.) Anxiety and the anxiety disorders. New Jersey: Erlbaum.

Stöber, J. (1997). Trait anxiety and pessimistic appraisal of risk and chance. Personality and Individual Differences, 22, 465-476.

Stroop, J. R. (1935). Studies of interference in serial verbal reactions. Journal of Experimental Psychology, 18, 643-662.

Tost, L. P., Gino, F., \& Larrick, R. (2012). Power, competitiveness, and advice taking: Why the powerful don't listen. Organizational Behavior and Human Decision Processes. In press.

Van Swol, L. M. \& Sniezek, J.A. (2005). Factors affecting the acceptance of expert advice. British Journal of Social Psychology, 44, 443-461.

Yaniv, I. (2004). Receiving other people's advice: Influence and benefit. Organizational Behavior and Human Decision Processes, 93, 1-13.

Yaniv, I. (1997). Weighting and trimming: Heuristics for aggregating judgments under uncertainty. Organizational Behavior and Human Decision Processes, 69, 237-249.

Yaniv, I., \& Foster, D. P. (1997). Precision and accuracy of judgmental estimation. Journal of Behavioral Decision Making, 10, 21-32.

Yaniv, I., \& Kleinberger, E. (2000). Advice taking in decision making: Egocentric discounting and reputation formation. Organizational Behavior and Human Decision Processes, 83(2), 260-281.

Yaniv, I., \& Milyavsky, M. (2007). Using advice from multiple sources to revise and improve judgment. Organizational Behavior and Human Decision Processes, 103, 104-120. 
Young, A. S., Klap, R., Shoai, R., \& Wells, K. B. (2008). Persistent depression and anxiety in the United States: Prevalence and quality of care. Psychiatric Services, 59, 1391-1398.

Zatz, S., \& Chassin, L. (1985). Cognitions of test anxious children under naturalistic test-taking conditions. Journal of Counseling and Clinical Psychology, 53, 393-401. 


\section{Tables}

Table 1

Mediation analyses, Experiment 1-6. The table reports standardized coefficients for each regression. $* * * p<.001, * * p<.01, * p<.05$

(a) Experiment 1

\begin{tabular}{lccc}
\hline & $\begin{array}{c}\text { Self-confidence } \\
X \rightarrow M\end{array}$ & $\begin{array}{c}\text { Advice seeking } \\
X \rightarrow Y\end{array}$ & $\begin{array}{c}\text { Advice seeking } \\
X, M \rightarrow Y\end{array}$ \\
\cline { 2 - 4 } Anxiety & & & $.44^{* * *}$ \\
Self-confidence & & $.24^{*}$ & .13 \\
\hline$R^{2}$ & $.19^{* * *}$ & & $-.26^{*}$ \\
\hline $95 \%$ bias-corrected CI & & $.06^{*}$ & $.11^{* *}$ \\
\hline
\end{tabular}

(b) Experiment 2

\begin{tabular}{lccc}
\hline & $\begin{array}{c}\text { Self-confidence } \\
X \rightarrow M\end{array}$ & $\begin{array}{c}\text { Advice taking } \\
X \rightarrow Y\end{array}$ & $\begin{array}{c}\text { Advice taking } \\
X, M \rightarrow Y\end{array}$ \\
\cline { 2 - 4 } Anxiety & $-.37 * * *$ & $.29 * *$ & .10 \\
Anger & $.32 * * *$ & $-.28 * *$ & -.11 \\
Self-confidence & & & $-.53 * * *$ \\
\hline$R^{2}$ & $.36^{* * *}$ & $.24 * * *$ & $.42 * * *$ \\
\hline $95 \%$ bias-corrected CI & & & {$[.05, .18]$} \\
\hline
\end{tabular}

(c) Experiment 3

\begin{tabular}{lccc|cc}
\hline & $\begin{array}{c}\text { Self-confidence } \\
X \rightarrow M\end{array}$ & $\begin{array}{c}\text { Advice quality } \\
X \rightarrow Y\end{array}$ & $\begin{array}{c}\text { Advice quality } \\
X, M \rightarrow Y\end{array}$ & $\begin{array}{c}\text { Advice taking } \\
X, M \rightarrow Y\end{array}$ & $\begin{array}{c}\text { Advice taking } \\
X, M \rightarrow Y\end{array}$ \\
\cline { 2 - 6 } & $-.32^{* *}$ & $.28^{*}$ & .07 & $.27^{*}$ & .12 \\
Anxiety & & & $-.67^{* * *}$ & & $-.46^{* * *}$ \\
Self-confidence & $.10^{* *}$ & $.08^{*}$ & $.48^{* * *}$ & $.07^{*}$ & $.26^{* * *}$ \\
\hline$R^{2}$ & & & {$[.19,1.11]$} & & {$[.24,2.04]$} \\
\hline $\begin{array}{l}95 \% \text { bias- } \\
\text { corrected CI }\end{array}$ & & & & & \\
\hline
\end{tabular}


(d) Experiment 4

\begin{tabular}{lccc}
\hline & $\begin{array}{c}\text { Self-confidence } \\
X \rightarrow M\end{array}$ & $\begin{array}{c}\text { Advice taking } \\
X \rightarrow Y\end{array}$ & $\begin{array}{c}\text { Advice taking } \\
X, M \rightarrow Y\end{array}$ \\
\cline { 2 - 4 } & & & \\
Anxiety & $-.72^{* * *}$ & $.34 * * *$ & $.18^{*}$ \\
Self-confidence & & & $-.47^{* * *}$ \\
\hline$R^{2}$ & $.12^{* * *}$ & $.12^{* * *}$ & $.31^{* * *}$ \\
\hline $95 \%$ bias-corrected CI & & & {$[.05, .21]$} \\
\hline
\end{tabular}

(e) Experiment $5 b$

\begin{tabular}{lccc}
\hline & $\begin{array}{c}\text { Self-confidence } \\
X \rightarrow M\end{array}$ & $\begin{array}{c}\text { Advice taking } \\
X \rightarrow Y\end{array}$ & $\begin{array}{c}\text { Advice taking } \\
X, M \rightarrow Y\end{array}$ \\
\cline { 2 - 4 } & $-.36^{* * *}$ & $.49^{* *}$ & $.22 * * *$ \\
Anxiety & .13 & $-.15^{*}$ & -.06 \\
Unreasonably high & .15 & -.14 & -.03 \\
Unreasonably low & & & $-.74 * * *$ \\
Self-confidence & $.14^{* * *}$ & $.25^{* * *}$ & $.72^{* * *}$ \\
\hline$R^{2}$ & & & {$[.13, .27]$} \\
\hline $95 \%$ bias-corrected CI & & & \\
\hline
\end{tabular}

(f) Experiment 5c

\begin{tabular}{lccc|cc}
\hline & Self-confidence & Advice quality & Advice quality & Advice taking & Advice taking \\
& $X \rightarrow M$ & $X \rightarrow Y$ & $X, M \rightarrow Y$ & $X, M \rightarrow Y$ & $X, M \rightarrow Y$ \\
\cline { 2 - 5 } Anxiety & $-.32^{* * *}$ & $.37^{* * *}$ & $.32^{* * *}$ & $.46^{* * *}$ & $.25^{* * *}$ \\
Advice accuracy & -.12 & $.36^{* * *}$ & $.34 * * *$ & .12 & .05 \\
Self-confidence & & & $-.18^{* *}$ & & $-.63^{* * *}$ \\
\hline$R^{2}$ & $.12^{* *}$ & $.26^{* * *}$ & $.29 * * *$ & $.22^{* * *}$ & $.57^{* * *}$ \\
\hline $95 \%$ bias- & & & {$[.03, .31]$} & & {$[.07, .25]$} \\
corrected CI & & & & & \\
\hline
\end{tabular}


(g) Experiment 6

\begin{tabular}{lccc}
\hline & $\begin{array}{c}\text { Self-confidence } \\
X \rightarrow M\end{array}$ & $\begin{array}{c}\text { Advice taking } \\
X \rightarrow Y\end{array}$ & $\begin{array}{c}\text { Advice taking } \\
X, M \rightarrow Y\end{array}$ \\
\cline { 2 - 4 } & $-.32 * * *$ & $.47 * * *$ & $.32 * * *$ \\
Anxiety & .07 & -.10 & -.06 \\
Advisor conflict & & & $-.47 * * *$ \\
Self-confidence & $.10^{* *}$ & $.22^{* * *}$ & $.42^{* * *}$ \\
\hline$R^{2}$ & & & {$[.06, .19]$} \\
\hline $95 \%$ bias-corrected CI & & & \\
\hline
\end{tabular}

Table 2

Means and standard deviations by condition, Experiment 2.

\begin{tabular}{lccccc}
\hline & $\begin{array}{c}\text { Feelings of } \\
\text { anxiety }\end{array}$ & $\begin{array}{c}\text { Neutral } \\
\text { feelings }\end{array}$ & $\begin{array}{c}\text { Feelings of } \\
\text { anger }\end{array}$ & $\begin{array}{c}\text { Advice taking } \\
\text { (DV) }\end{array}$ & $\begin{array}{c}\text { Self-confidence } \\
\text { (mediator) }\end{array}$ \\
\cline { 2 - 6 } Anxiety & $4.46(1.39)$ & $2.45(1.57)$ & $1.75(1.02)$ & $0.51(0.30)$ & $3.21(1.14)$ \\
Neutral condition & $1.97(1.51)$ & $3.50(1.68)$ & $1.55(1.12)$ & $0.36(0.16)$ & $4.09(0.74)$ \\
Anger condition & $2.23(1.49)$ & $2.81(1.45)$ & $3.09(1.24)$ & $0.21(0.14)$ & $4.84(0.72)$ \\
\hline
\end{tabular}




\section{Figure Captions}

Figure 1. Theoretical model

Figure 2. Interaction of emotion and advice quality on perceived advice quality (Experiment 5a)

Figure 3. Interaction of emotion and advice quality on advice taking (Experiment 5b)

Figure 4. Interaction of emotion and conflict of interest on advice taking (Experiment 6) 
Figure 1

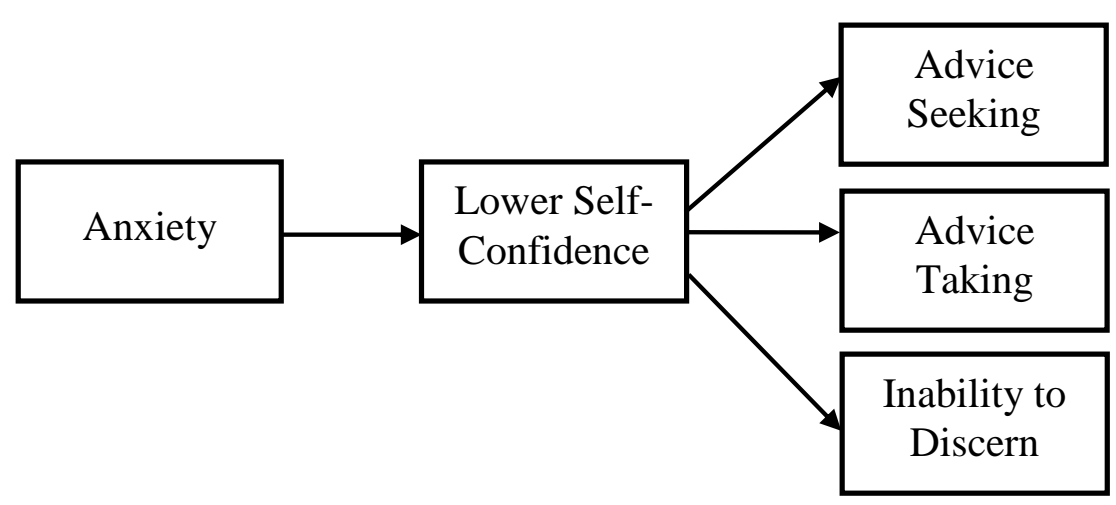


Figure 2

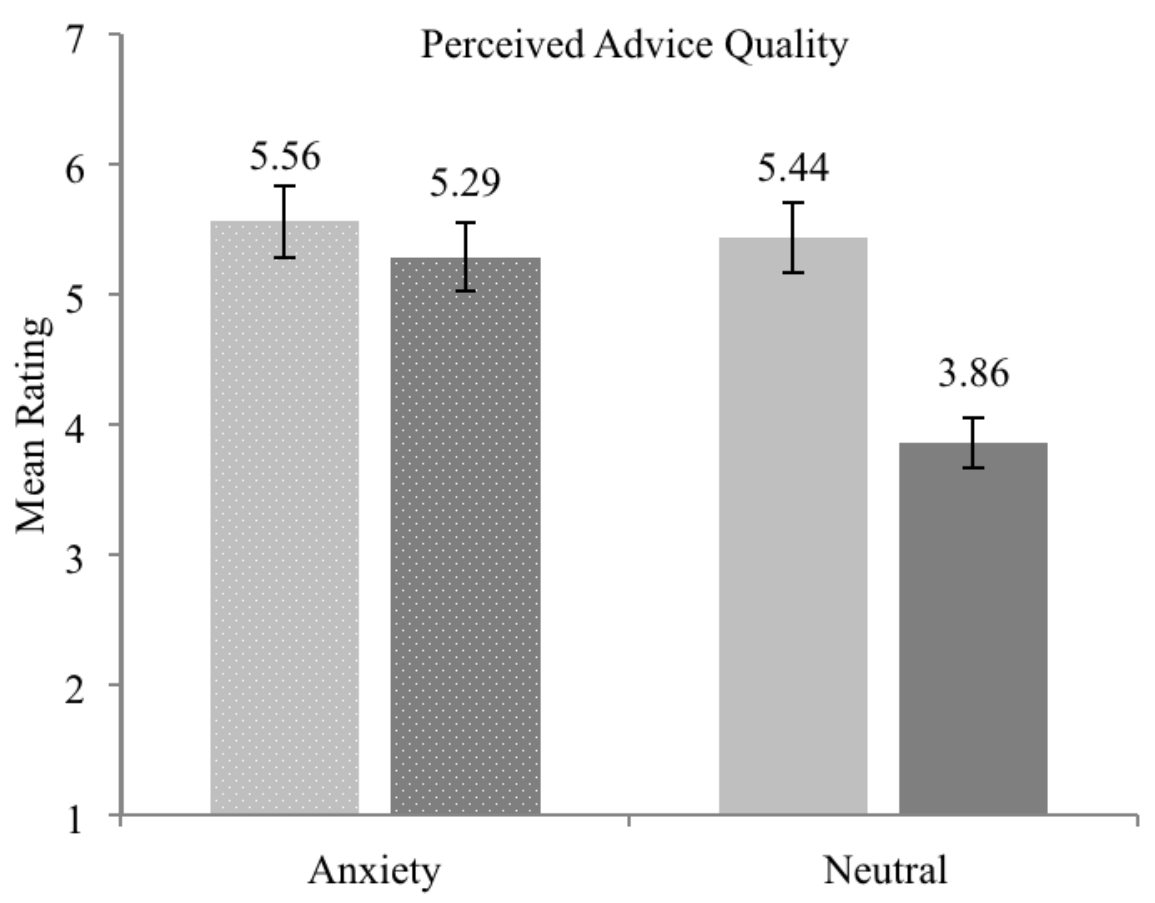

Reasonable Advice

- Unreasonable Advice 
Figure 3

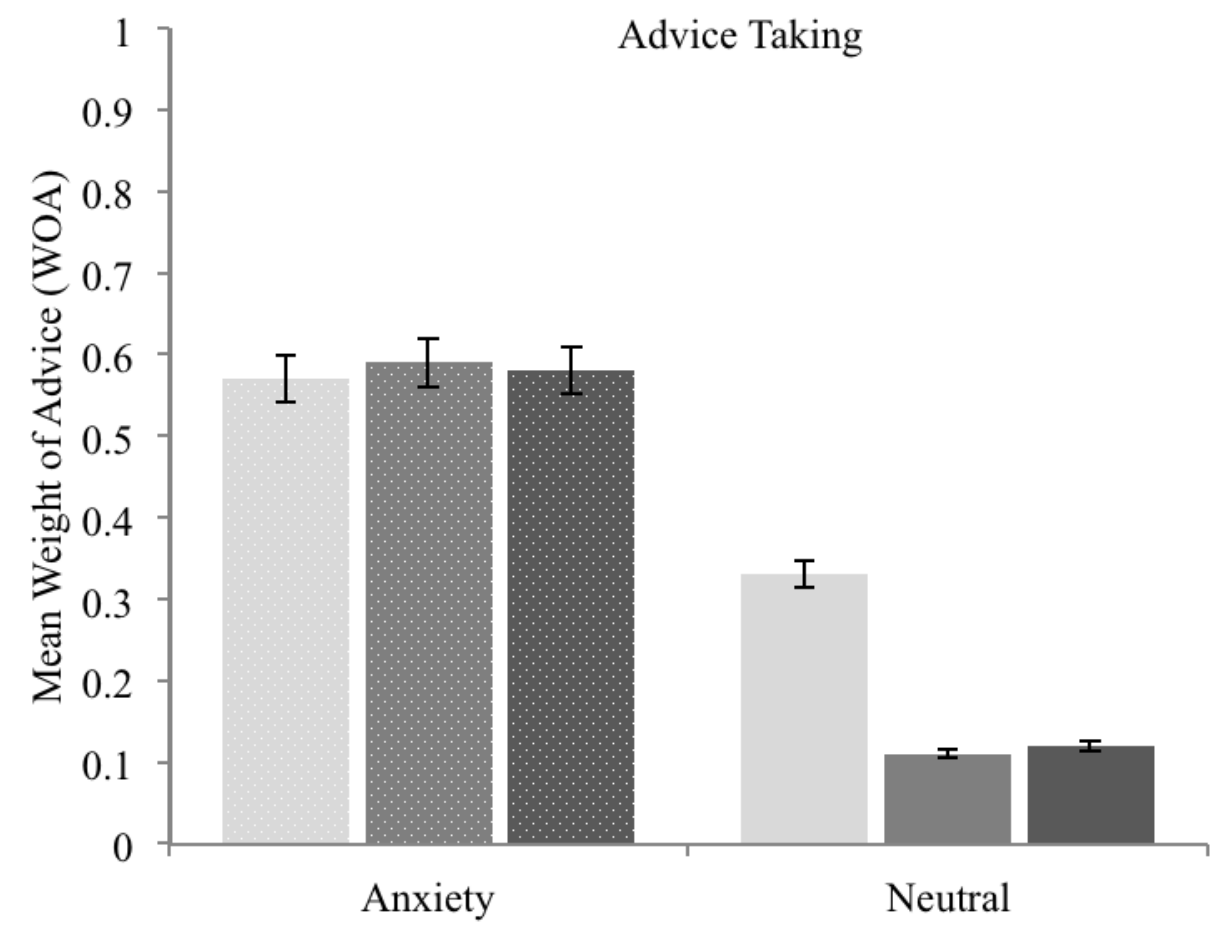

Reasonable Advice

- Unreasonably Low Advice

- Unreasonably High Advice 
Figure 4

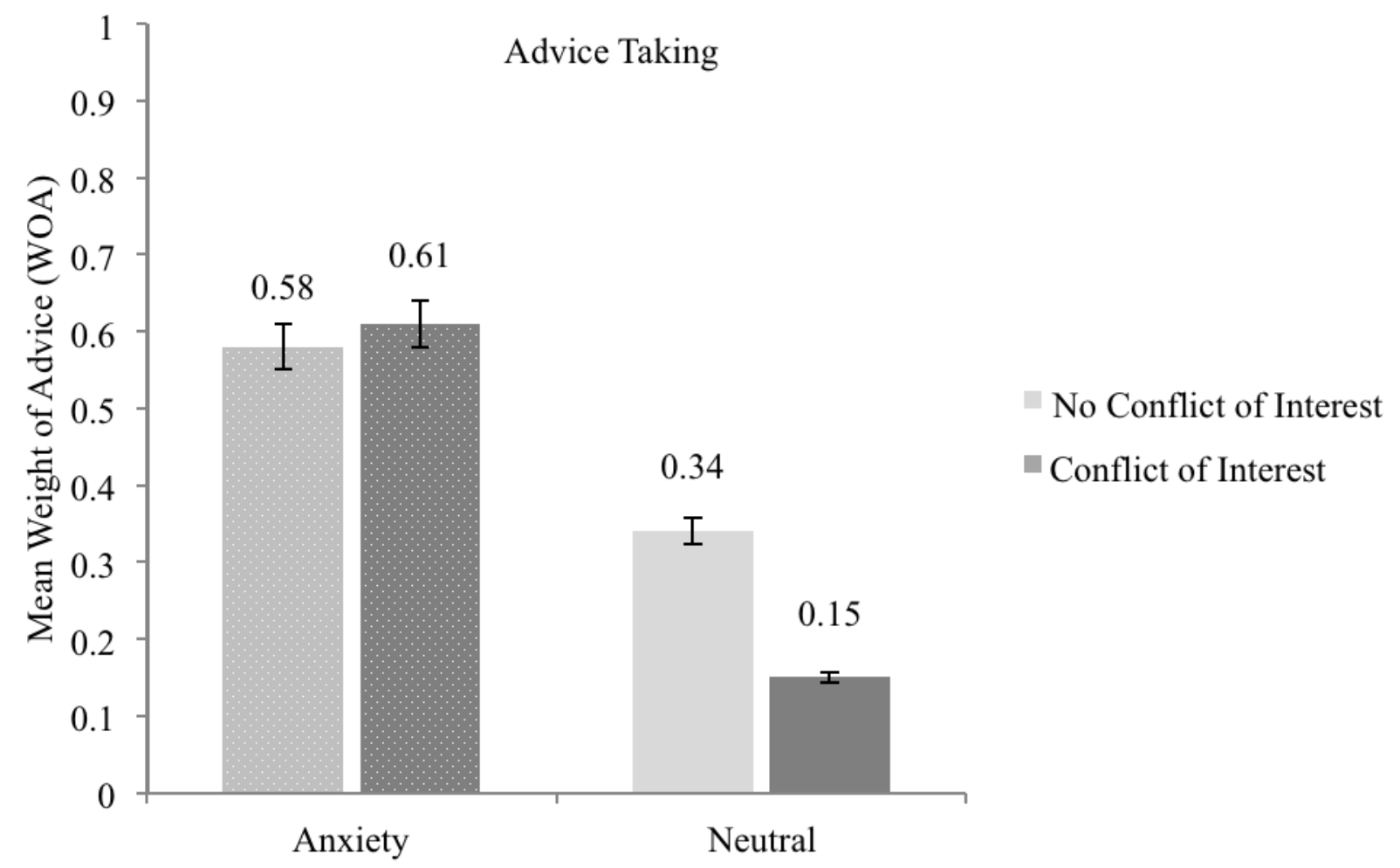

